\title{
Synthesis and characterization of Eu3+ doped TiO2 thin films deposited by spray pyrolysis technique for photocatalytic application
}

Shereen Alshomar ( $\nabla$ shereen-m@hotmail.com )

Ha'il University

Research

Keywords: TiO2,europium, doping, spray pyrolysis, photocatalytic

Posted Date: October 13th, 2020

DOI: https://doi.org/10.21203/rs.3.rs-91010/v1

License: (c) (1) This work is licensed under a Creative Commons Attribution 4.0 International License.

Read Full License 


\title{
Synthesis and characterization of $\mathrm{Eu}^{3+}$ doped $\mathrm{TiO}_{2}$ thin films deposited by spray pyrolysis technique for photocatalytic application
}

\section{S. M alshomar ${ }^{1}$}

\begin{abstract}
${ }^{1}$ Physics Department, Faculty of Science, Ha'il University, Hail, Saudi Arabia
*Corresponding author: E-mail address, shereen-m@ hotmail.com

s.alshomar@uoh.edu.sa
\end{abstract}

\section{Abstract:}

In this study, nanocrystalline $\mathrm{TiO}_{2}: \mathrm{Eu}^{3+}$ thin films are successfully formed by spray pyrolysis technique deposited on glass substrate. Optical, electrical, structure, surface morphology, and photocatalytic degradation of Methylene blue have been examined. The optical properties of the films are analyzed using transmittance and reflectance spectra, which are measured using UVVis-NIR double-beam spectrophotometer. Optical properties such as refractive index $(\mathrm{n})$, extinction coefficient $(\mathrm{k})$, optical conductivity $(\sigma)$ and Urbach energy $\left(\mathrm{E}_{u}\right)$ have been calculated as a function of $\mathrm{Eu}^{3+}$ concentration. Film thickness were evaluated using the refractive index dependence on wavelength . The films thickness were determined as 97.13, $122.62,123.24,117.14$ and $128.25 \mathrm{~nm}$, respectively, for Eu doped $\mathrm{TiO}_{2}$ at $0,4,6,8$ and 10 wt $\%$ doping concentration. The band gap values raised from 3.29 to $3.42 \mathrm{eV}$ with increasing the $\mathrm{Eu}^{3+}$ dopant concentration. The highest electrical conductivity was found to be $3.01 \times 10^{-2}(\Omega . \mathrm{cm})^{-1}$ at high doping level with $10 \mathrm{wt} \% \mathrm{Eu}^{3+}$. The XRD analysis illustrate the tetragonal crystal structure of films with anatase phase and reduces crystallite size 
linearly with increasing $\mathrm{Eu}^{3+}$ concentration. Scanning electron microscopy (SEM) analysis indicated consistent allocation of irregular and spherical shaped grains covering the substrate surface. The average grain size in range of $82.5-51.1 \mathrm{~nm}$ is observed and films show porous nature. The photocatalytic effect of $\mathrm{TiO}_{2}$ : $\mathrm{Eu}^{3+}$ thin films is predicted from the degradation of methylene blue (MB) at room temperature under UV light irradiation. An enhancement in photocatalytic degradation observed by increasing the amount of $\mathrm{Eu}^{3+}$ due to increase in the e/h pair production and increase of film thickness. These results make $\mathrm{TiO}_{2}: \mathrm{Eu}^{3+}$ thin films as attractive candidate for photovoltaic cells and other optoelectronic device applications

Keywords: , $\mathrm{TiO}_{2}$,europium, doping, spray pyrolysis, photocatalytic .

\section{Introduction:}

Research on $\mathrm{TiO}_{2}$ has drawn a lot of interest due to its unique characteristics. $\mathrm{TiO}_{2}$ is a wide band gap semiconductor, nontoxic material, high hardness, displays a large range of electrical conductivity, shows mechanical and chemical stability, low cost materials with high light conversion efficiency and high dielectric constant. ${ }^{1-3}$ It is suitable for many applications such as gas sensor, solar cell, bio-medical product, water treatment and optoelectronic device. ${ }^{4-5}$ Many studies have been focused to improve the optical, electrical and photocatalytic activity of $\mathrm{TiO}_{2}$ by dye sensitizing and surface deposition with rare earth metals doping. 
Rare-earth doped semiconductor has been used in in several applications including cathode ray tube (CRT) displays, solid-state lasers, sensors, fluorescent markers, radiation detection and medical applications. ${ }^{6}$ The motivation for the use of rare earth dopants in these applications arise from the bright, spectrally narrow emissions, largely irrespective of the host material. Rare earth ions display a robust release due to $4 \mathrm{f}-4 \mathrm{f}$ movement of electrons from top to bottom level. ${ }^{7}$ RE ions doped semiconductor collect the organic impurities on the surface due to the formation of lanthanide ions complexes with Lewis centers (e.g., organic acids, amines, aldehydes and alcohols). The interaction between functional groups and f-orbital increase the efficiency to separate electrons and holes. ${ }^{8}$ In trivalent rare earth ions the $4 \mathrm{f}$ orbital is incomplete while the $5 \mathrm{~s}$ and $5 \mathrm{p}$ orbitals are filled, resulting in $4 \mathrm{f}$ orbital comprises the $5 \mathrm{~s}$ and $5 \mathrm{p}$ orbitals consequences electron transitions within the incomplete $4 \mathrm{f}$ orbital and shielding of the $4 \mathrm{f}$ states from the electric field of the host. Titanium oxide can construct complexes of $\mathrm{f}$ orbitals that absorb external ions near the surface and tune the band gap by improving photocatalytic movement. ${ }^{9}$ Among the rare earth elements, $\mathrm{Eu}^{3+}$ (Erbium) ions are more suitable for doping with $\mathrm{TiO}_{2}$ du to its excellent Optical, properties, high photocatalytic activity and chemical performance. $\mathrm{Eu}^{3+}$ has unique luminance properties because of sharp emission of radiation in visible range attributed to intra $4 \mathrm{f}$ and $4 \mathrm{f}-5 \mathrm{~d}$ transition. ${ }^{10}$

There are several approaches to prepare $\mathrm{Eu}^{3+}$ doped $\mathrm{TiO}_{2}$ in variant forms due to its strong dependence on preparation technique, doping concentration, films thickness and particles size. Leostean et al. (2013) ${ }^{4}$ prepared nanoparticles of Eu doped $\mathrm{TiO}_{2}$ using some organic additives such as polyethylene glycol 600 and methacrylic acid (MA). They found $\mathrm{TiO}_{2}$ : Eu nanoparticles shows high 
capacity to absorb organic additive lead to red luminescence which associated with XRD and TEM results. Zhu et al.(2014). ${ }^{11}$ The electroluminescence effect of TiO2/p+-Si heterostructure devices has been investigated by $\mathrm{TiO}_{2}$ : $\mathrm{Eu}$ films and annealing temperature. It has been reported, the high $\mathrm{Eu}$ concentration and annealing temperature, the transfer of energy $\mathrm{TiO}_{2}$ host to $\mathrm{Eu}^{3+}$ ions display red electroluminescence from $\mathrm{TiO}_{2}: \mathrm{Eu} / \mathrm{p}+-\mathrm{Si}$ heterostructures. The influence of particle size and Eu-doped $\mathrm{TiO}_{2}$ nanophosphor on optical behavior has been studied by Raman spectra and photoluminescence. The films demonstrate the PL discharge ${ }^{5} \mathrm{D}_{0} \rightarrow{ }^{7} \mathrm{~F}_{\mathrm{J}}(\mathrm{J}=0$, $1,2,3,4,5)$ due to changing within $\mathrm{Eu}^{3+}$ ions at wavelength $393 \mathrm{~nm}$ in the near visible region. ${ }^{12}$ A high photocatalytic activity response with a rise in $\mathrm{Eu}$ content was observed. However, Amorphous titania particles doped with $\mathrm{Eu}(\mathrm{III})$ acetylacetonate with atypical molar $\mathrm{Eu} / \mathrm{Ti}$ ratios are elaborated at concentration of $\mathrm{Eu}=0.125,0.5,2.0$ and 5.0 using sol gel method was studied. ${ }^{13}$ It was observed that ideal Eu/Ti value (0.5) that displayed greatest luminescence. Moreover, the $\mathrm{Eu}(\mathrm{acac})^{3}$ doping is suitable for optoelectronic, organic, and environmental purposes.

Moreover, to modify optical and biological findings of $\mathrm{TiO}_{2}$ thin films by doping with rare earth element, researchers are trying to change the synthesis process. Among the mostly used process magnetron sputtering, ${ }^{14}$ plasma oxidation, ${ }^{15}$ sol gel, ${ }^{16}$ spray pyrolysis, ${ }^{17}$ electrospinning, ${ }^{18}$ hydrothermal method and pulsed laser deposition (PLD). ${ }^{19}$ The spray pyrolysis method is considered as a simple and low cost method. It has capability to produce wide variety of nanostructured materials with high quality, and homogenous films of different doping elements on different substrates, which can be used as sensors and other application. 
In this article, we concern on investigation the effects of dopant concentration on physical findings of $\mathrm{Eu}^{3+}$ doped $\mathrm{TiO}_{2}$ thin films. The purpose of present work is focused on synthesize of $\mathrm{TiO}_{2}: \mathrm{Eu}^{3+}$ thin film nanostructures by spray pyrolysis method and studied its optical, electrical, structural, surface morphology and photocatalytic properties at different doping concentration.

\section{Experimental:}

\section{i. Preparation of pure $\mathrm{TiO}_{2}$ solution:}

First $1.6 \mathrm{ml}$ Titanium (IV) isopropoxide Ti $\left(\mathrm{OC}_{3} \mathrm{H}_{7}\right)_{4}$ ( purity 98.0\%,Sigma Aldrich) was dissolved with $4.5 \mathrm{ml}$ of isopropanol and $5.15 \mathrm{ml}$ of acetic acid $\left(\mathrm{CH}_{3} \mathrm{COOH}\right)$ (Sigma Aldrich) was added. Then the solution stirred with a magnetic stirrer at $60{ }^{\circ} \mathrm{C}$ for $15 \mathrm{~min}$. After stirring $12 \mathrm{ml}$ of ethanol (purity 99.9\%) mixed with the solution and then stirred for 2 hours at $60^{\circ} \mathrm{C}$.

\section{ii. Preparation of $\mathrm{Eu}^{+3}$ doped $\mathrm{TiO}_{2}$ solution:}

$\mathrm{Eu}\left(\mathrm{NO}_{3}\right)_{3}$ (purity $99.9 \%$ ) was used as a Erbium source. To prepare the different rates $(4,6,8$ and $10 \mathrm{wt} \%), \mathrm{Eu}^{3+}$ doped $\mathrm{TiO}_{2}$ solutions were prepared by dissolved calculated amount of compound $\mathrm{Eu}\left(\mathrm{NO}_{3}\right)_{3} 3 \mathrm{ml}$ of isopropanol and acetic acid then mixed at room temperature for $15 \mathrm{~min}$. The resulting solutions were added dropwise to pure $\mathrm{TiO}_{2}$ solution under constant stirring for 1 hour at $60{ }^{\circ} \mathrm{C}$. The final solutions were kept in the beakers and aged for 24 hours before films deposition.

\section{iii. Films deposition:}

The films deposited on glass substrates using spray pyrolysis method. Prior to the deposition of the thin film, the glass substrates were pre-cleaned with 
an acetone, ethanol and distilled water using ultrasonic cleaner to improve their adhesion nature. The cleaned substrates were dried for $10 \mathrm{~min}$ before use. The pure and doped solution with different doping concentration $(0,4$, 6, 8 and $10 \mathrm{wt} \%$ ) of $\mathrm{Eu}^{3+}$ was backed-up in a spray container and dispersed the solution on the glass substrate to prepare uniform films. Deposition parameters such as spray time, nozzle diameter, substrate temperature, and spray nozzle- substrate distance were kept constant during the whole deposition process. The spraying time was about $15 \mathrm{~s}$ with the period between spraying processes was about 3 min to avoid cooling of the substrates and a nozzle diameter of $0.7 \mathrm{~mm}$. The glass substrate temperature was $350^{\circ} \mathrm{C}$ and air pressure was 1 bar. The height of spraying nozzle was 35 $\mathrm{cm}$ during the deposition process. After the deposition of the thin layers, the resulting thin films were annealed at $400{ }^{\circ} \mathrm{C}$ in air at a heating rate of 5 ${ }^{\circ} \mathrm{C} / \mathrm{min}$ and cooled down to room temperature.

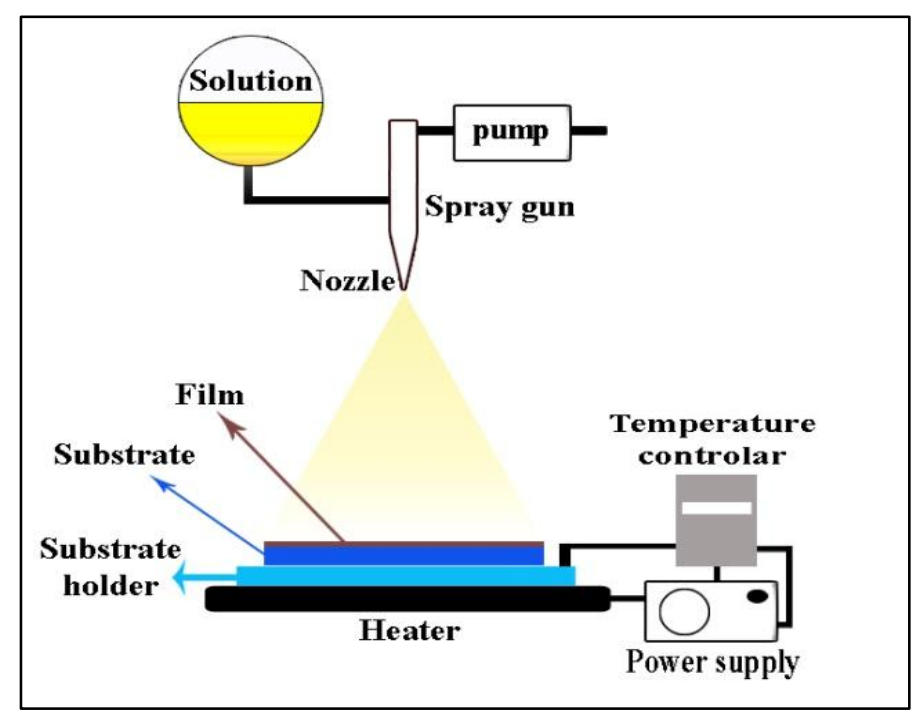

FIG.1. spray pyrolysis set up. 


\section{Characterization:}

Optical properties of thin films obtained using UV-Vis-NIR double-beam spectrophotometer in $250-800 \mathrm{~nm}$ range at room temperature. The electrical characterizations of samples were investigated by four-point probe method (KIETHLEY Instrument). X-ray diffractometer (XRD) (Model JSDX-60PA) with monochromatic high- intensity $\mathrm{Cu} \mathrm{K \alpha}$ radiation $(\lambda=0.154184 \mathrm{~nm})$ in the scanning range of $(2 \theta)$ was between $20^{\circ}$ and $80^{\circ}$ with a slow scanning speed $(1 \% \mathrm{~min})$ and a minor time constant $(1 \mathrm{~s})$ used to study the structural properties of as-deposited films. The surface morphology of the films was investigated by field emission scanning electron microscopy (FE-SEM) (JEOL JSM-6500) at $10 \mathrm{kV}$. Photovoltaic characteristics of the samples were tested using Methylene Blue degradation at room temperature, which is used as a model contaminant. The photocatalytic degradation measured by UVVis double-beam spectrophotometer at an incident wavelength of $665 \mathrm{~nm}$. The estimation done under UV light $50 \mathrm{~W}$ xenon lamp (Electro-Technic Products, USA) as a source of UV light.

\section{Result and discussion:}

\section{i. Optical studies:}

\section{Transmittance :}

Optical transmittance of undoped and various $\mathrm{TiO}_{2}: \mathrm{Eu}^{3+}$ thin films against wavelength were illustrated in Figure 2. The transmittance of light visible range for undoped $\mathrm{TiO}_{2}$ thin films is over $65 \%$. However the transparency of $\mathrm{TiO}_{2}$ : $\mathrm{Eu}^{3+}$ films enhance up to $80 \%$ with increase the doping concentration. These results show that the highest transmittance at high doping concentration due to the minimized of light scattering with doping. ${ }^{20}$ 


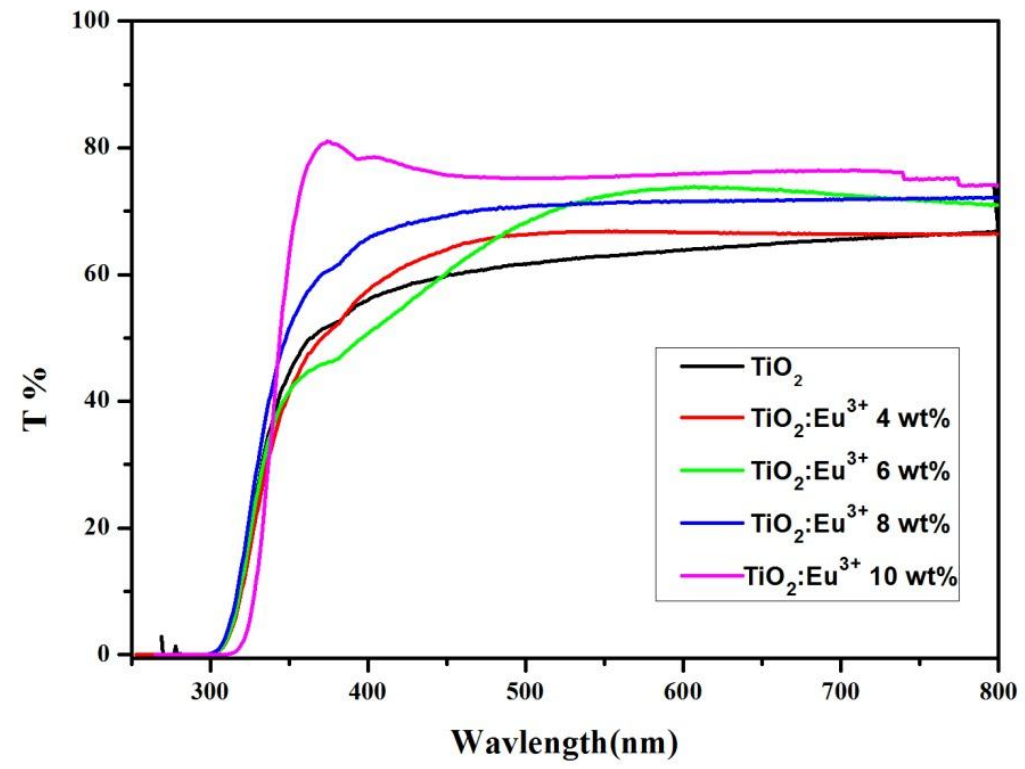

FIG.2. Transmission spectra of undoped and $\mathrm{TiO}_{2}: \mathrm{Eu}^{3+}$ thin films.

\section{Reflectance:}

The reflectance spectra of undoped and $\mathrm{TiO}_{2}: \mathrm{Eu}^{3+}$ films were shown in figure 3. It was observed that reflectance ability of undoped $\mathrm{TiO}_{2}$ thin film is higher compared to reflectance ability of doped films. This is the consequence of structural disorder in $\mathrm{TiO}_{2}$ lattice and change the films thickness. ${ }^{21}$

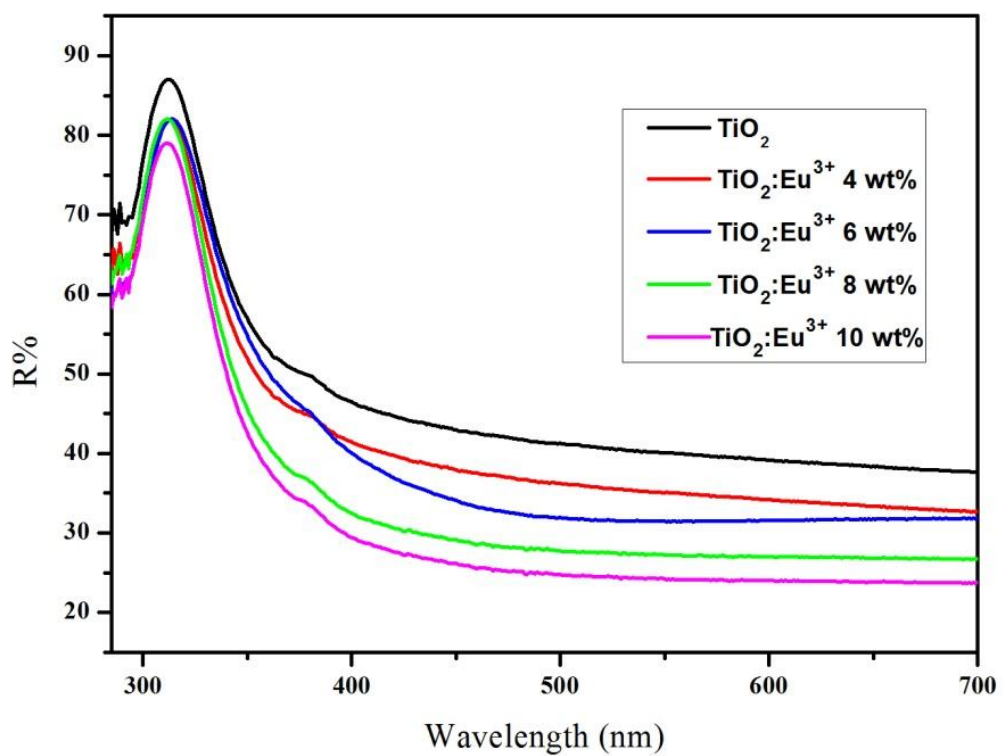

FIG. 3. Reflectance spectra of undoped and $\mathrm{TiO}_{2}: \mathrm{Eu}^{3+}$ thin films. 


\section{Refractive index:}

The refractive index for undoped and $\mathrm{TiO}_{2}: \mathrm{Eu}^{3+}$ thin films at different wavelengths were calculated using $\operatorname{Eq}(1):{ }^{22}$

$n=\frac{(1+R)^{0.5}}{(1-R)^{0.5}}$

Where $n$ is the refractive index and $R$ is the reflectance

The refractive index, $n$, of undoped and $\mathrm{TiO}_{2}: \mathrm{Eu}^{3+}$ films deposited at different doping concentration is depicted in Figure 4. The $n(\omega)$ values show a general decrease as the wavelength increases for all films and tend to decrease with increasing $\mathrm{Eu}^{3+}$ doping. The introducing of $\mathrm{Eu}^{3+}$ atoms may increase the films density. For this reason, the refractive index at high doping concentration, get smaller which can be explained by the tendency of $\mathrm{Eu}^{3+}$ nanoparticles to fully oxidize phase $\mathrm{Eu}_{3} \mathrm{O}_{2}$. A similar behavior has been reported for $\mathrm{Cr}$ doped $\mathrm{TiO}_{2}$ thin films are formed by magnetron cosputtering process. ${ }^{23}$

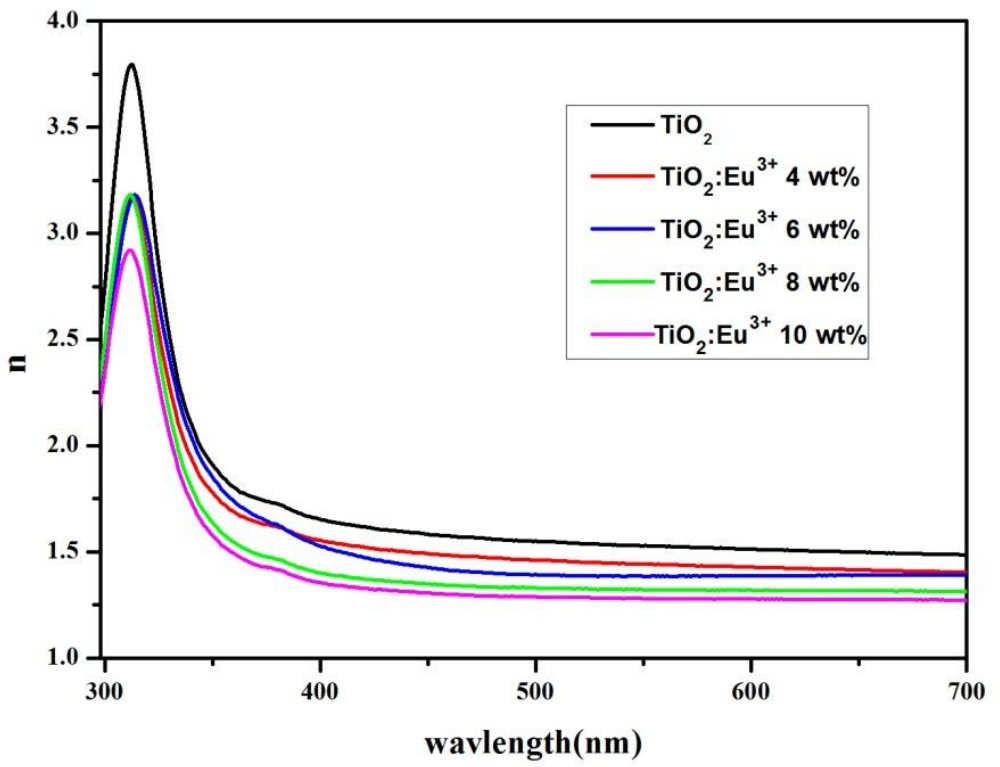

FIG. 4. Effect of doping concentration on refractive index of undoped and $\mathrm{TiO}_{2}: \mathrm{Eu}^{3+}$ thin films. 


\section{Thickness:}

Films thickness can be evaluated by using the $\operatorname{Eq}(2)$ below: ${ }^{24}$

$d=\frac{\lambda_{1} \lambda_{2}}{\left(n_{1} \lambda_{2}-n_{2} \lambda_{1}\right)}$

Here $\lambda_{1}$ and $\lambda_{2}$ are the consecutive wavelength of maxima and minima while $\mathrm{n}_{1}$ and $\mathrm{n}_{2}$ are their refractive indices. Table I summarizes the thickness (d), refractive index (n) of the undoped, and $\mathrm{TiO}_{2}$ : $\mathrm{Eu}^{3+}$ prepared at different doping concentration. Where un doped films show lower thickness. Films thickness depends on the initial amount of solution spread on the substrate thus the thickness varies with doping concentration.

Table I. Thickness and refractive index of the undoped, and $\mathrm{TiO}_{2}: \mathrm{Eu}^{3+}$.

\begin{tabular}{cccccc}
\hline \hline Sample & $\begin{array}{c}\lambda_{1} \\
(\mathrm{~nm})\end{array}$ & $\mathrm{n}_{1}$ & $\begin{array}{c}\lambda_{2} \\
(\mathrm{~nm})\end{array}$ & $\mathrm{n}_{2}$ & $\begin{array}{c}\mathrm{d} \\
(\mathrm{nm})\end{array}$ \\
\hline $\mathrm{TiO}_{2}$ & 312 & 3.796 & 798 & 1.494 & 97.13 \\
$\mathrm{TiO}_{2}: \mathrm{Eu}^{3+} 4 \mathrm{wt} \%$ & 313 & 3.181 & 699 & 1.403 & 122.62 \\
$\mathrm{TiO}_{2}: \mathrm{Eu}^{3+} 6 \mathrm{wt} \%$ & 314 & 3.183 & 687 & 1.390 & 123.24 \\
$\mathrm{TiO}_{2}: \mathrm{Eu}^{3+} 8 \mathrm{wt} \%$ & 312 & 3.180 & 791 & 1.310 & 117.14 \\
$\mathrm{TiO}_{2}: \mathrm{Eu}^{3+} 10 \mathrm{wt} \%$ & 311 & 2.92 & 797 & 1.269 & 128.25 \\
\hline \hline
\end{tabular}

\section{Extinction coefficient:}

The extinction coefficient $(\mathrm{k})$ is calculated by $\operatorname{Eq}(3):{ }^{25}$

$k=\frac{\alpha \lambda}{4 \pi}$

Where $\alpha$ was determined using the relation(4): ${ }^{26}$

$\alpha=2.303 \times\left(\frac{A}{d}\right)$ 
Where $\mathrm{A}$ is the absorbance and $\mathrm{d}$ is the films thickness.

Figure 5 shows the change in extinction coefficient of $\mathrm{TiO}_{2}: \mathrm{Eu}^{3+}$ thin films with wavelength. It's clear from the figure that the extinction coefficient at $280 \mathrm{~nm}$ decrease for un doped and $\mathrm{TiO}_{2}: \mathrm{Eu}^{3+}$ films. This may be attributed to energy loss because of scattering and dispersion with increasing wavelength. These results confirm what we mentioned before that $\mathrm{TiO}_{2}$ : $\mathrm{Eu}^{3+}$ films are transparent for visible light.

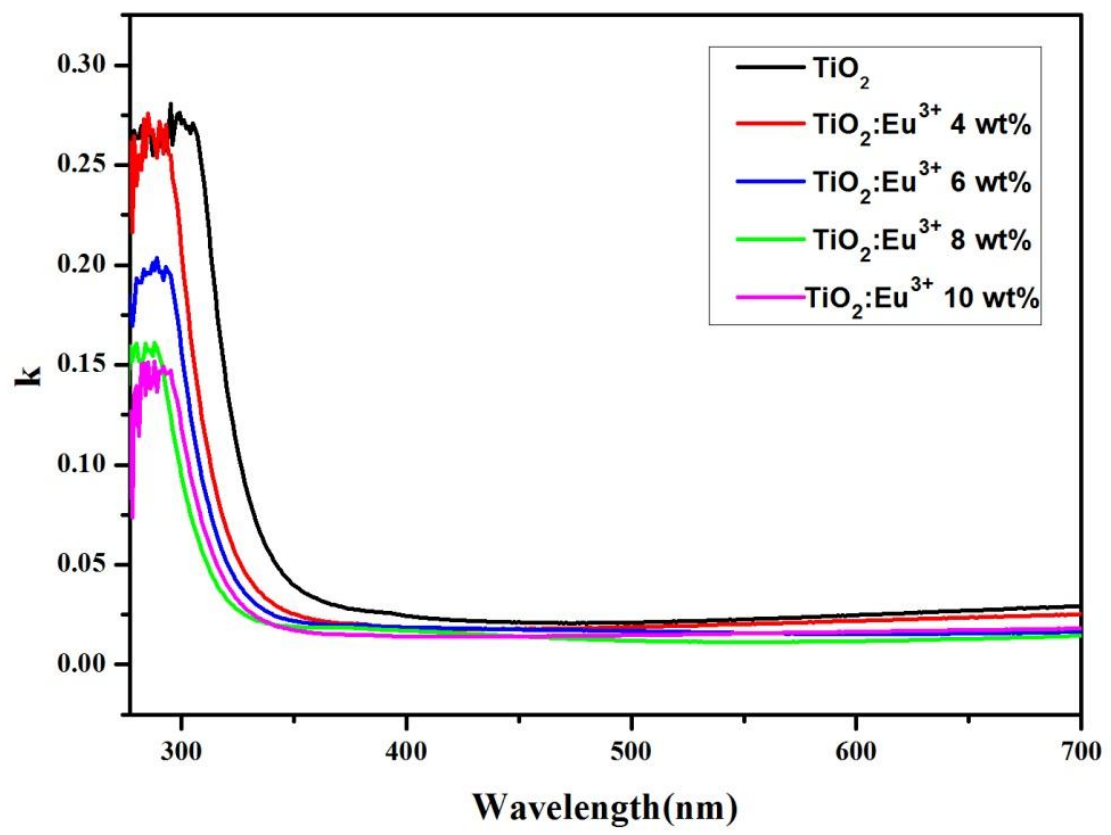

FIG. 5. Effect of doping concentration on extinction coefficient of undoped and $\mathrm{TiO}_{2}: \mathrm{Eu}^{3+}$ thin films.

\section{Optical band gap:}

The optical band gaps for un doped $\mathrm{TiO}_{2}$ and $\mathrm{TiO}_{2}: \mathrm{Eu}^{3+}$ has been computed by UV-vis spectra and presented in Figure 6 by Tauc Eq (5) below: 
$\alpha h v=A\left(h v-E_{g}\right)^{n}$

Where $\alpha$ is absorption coefficient, $\mathrm{h}$ is plank constant, $v$ is frequency, $\mathrm{A}$ and $\mathrm{n}$ are constant and $\mathrm{E}_{\mathrm{g}}$ is optical band gap. For direct, forbidden, and indirect transitions the values of refractive indices are reported as $n=1 / 2,2 / 3$, and 2 , respectively. ${ }^{27}$ The obtained band gap results are presented in Table II. The detected values were higher than the band gap of bulk $\mathrm{TiO}_{2}$ in anatas phase which value is $3.18 \mathrm{e} \mathrm{V} .{ }^{28}$ The Increment in band gaps of $\mathrm{Eu}^{3+}$ doping $\mathrm{TiO}_{2}$ thin films oxygen partial pressure on it. This caused the extension of the band -tail into the band gap, ${ }^{29}$ growth defect, charge impurities, disorder at the grain boundary and Burstein Moss effect. Where the bottom states of conduction band are stopped transition occur in levels higher energy than Fermi energy. In contrast, Camps et al.(2017). ${ }^{1}$ has been reported that the presence of Eu doping with $\mathrm{TiO}_{2}$ thin films prepared through laser-assisted technique reduces the band gap because of creation of impurities and new energy states within $\mathrm{TiO}_{2}$ band gap.

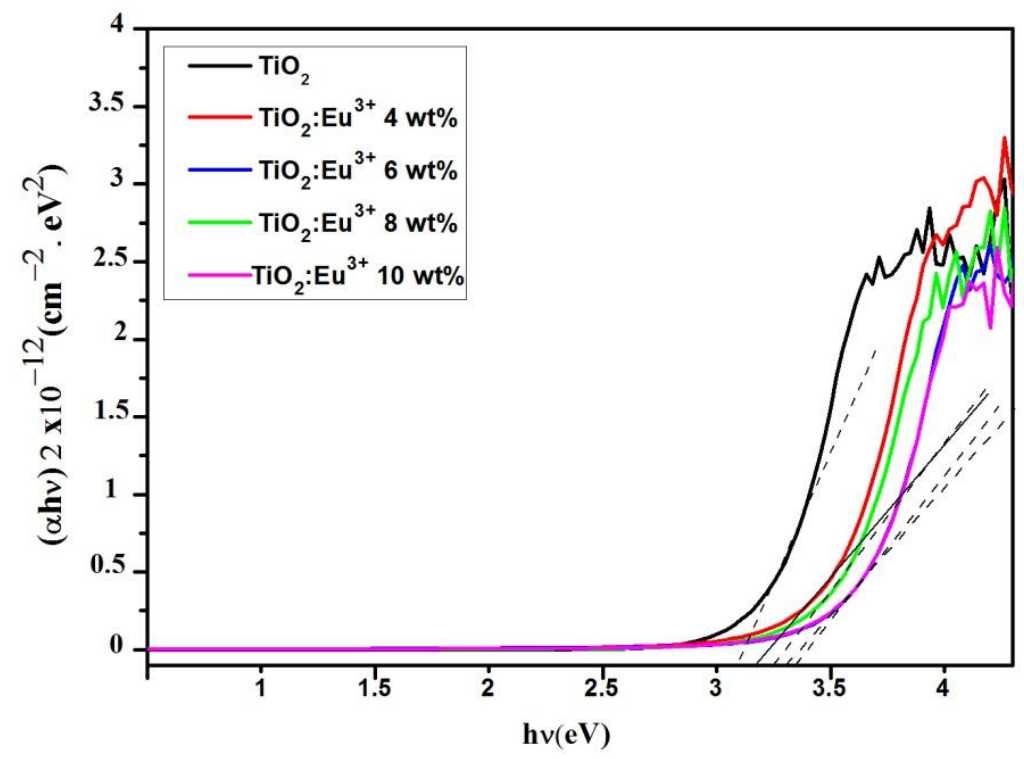

FIG. 6. Direct band gap plot of undoped and $\mathrm{TiO}_{2}: \mathrm{Eu}^{3+}$ thin films. 


\section{Urbach energy:}

The Urbach energy $\mathrm{E}_{u}$ for undoped and $\mathrm{TiO}_{2}: \mathrm{Eu}^{3+}$ thin films was calculated formula(6): ${ }^{30}$

$\alpha=\alpha_{0}+e^{\frac{h v}{E_{u}}}$

Where $\alpha$ is absorption coefficient and $\alpha_{0}$ indicates the a constant. Urbach energy is determined for undoped and $\mathrm{TiO}_{2}: \mathrm{Eu}^{3+}$ thin films from the slope of $\operatorname{In}(\alpha)$ versus energy graph (See Figure 7). as shown in figure (7). The computed urbach energy is reported in Table II. It is noted that there was a significant decrease in the Urbach energy with doping. The undoped film had a value of $23.03 \mathrm{~m} \mathrm{eV}$ compared to $\mathrm{TiO}_{2}: \mathrm{Eu}^{3+}$ films. The change in Urbach energy due to introduce impurity level and defect in the band structure after doping either on the conduction band or valence band or both conduction and valence bands. These results are very good agreement with literature. ${ }^{31}$

Table II. Variation of band gap and Urbach energy of the undoped, and $\mathrm{TiO}_{2}: \mathrm{Eu}^{3+}$ films

\begin{tabular}{ccc}
\hline Sample & $\begin{array}{c}\text { Energy gap Eg } \\
(\mathrm{eV})\end{array}$ & $\begin{array}{c}\text { Urbach energy Eu } \\
(\mathrm{meV})\end{array}$ \\
\hline $\mathrm{TiO}_{2}$ & 3.29 & 23.03 \\
$\mathrm{TiO}_{2}: \mathrm{Eu}^{3+} 4 \mathrm{wt} \%$ & 3.33 & 21.23 \\
$\mathrm{TiO}_{2}: \mathrm{Eu}^{3+} 6 \mathrm{wt} \%$ & 3.37 & 19.63 \\
$\mathrm{TiO}_{2}: \mathrm{Eu}^{3+} 8 \mathrm{wt} \%$ & 3.40 & 17.35 \\
$\mathrm{TiO}_{2}: \mathrm{Eu}^{3+} 10 \mathrm{wt} \%$ & 3.42 & 13.25 \\
\hline \hline
\end{tabular}




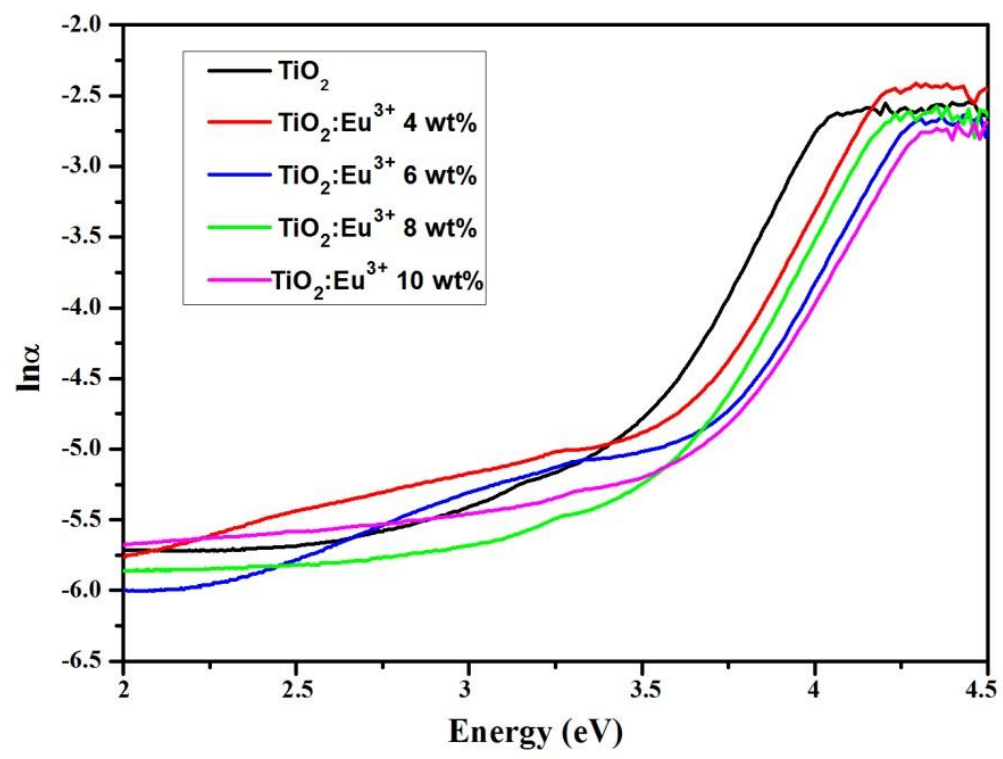

FIG. 7. Urbach plot of undoped and $\mathrm{TiO}_{2}: \mathrm{Eu}^{3+}$ thin films.

\section{Optical conductivity:}

Optical conductivity, $\sigma$ is found from the values of absorption coefficient $\alpha$ and the speed of light by using formula (7): ${ }^{27}$

$\sigma=\frac{\alpha n c}{4 \pi}$

The Figure 8 shows the plot between $\sigma$ with photon energy of undoped and all $\mathrm{TiO}_{2}: \mathrm{Eu}^{3+}$ films for various concentrations. From the graph, it is noticeably clear that in the low-energy region, optical conductivity values of un doped and doped films were close to each other. However, at high-energy region the doped films are having high optical conductivity than un doped films due to electron exited by photon energy and also optical conductivity tend to increase with increasing $\mathrm{Eu}^{3+}$ doping. High optical conductivity of $\mathrm{TiO}_{2}: \mathrm{Eu}^{3+}$ that makes it suitable for optical device application. 


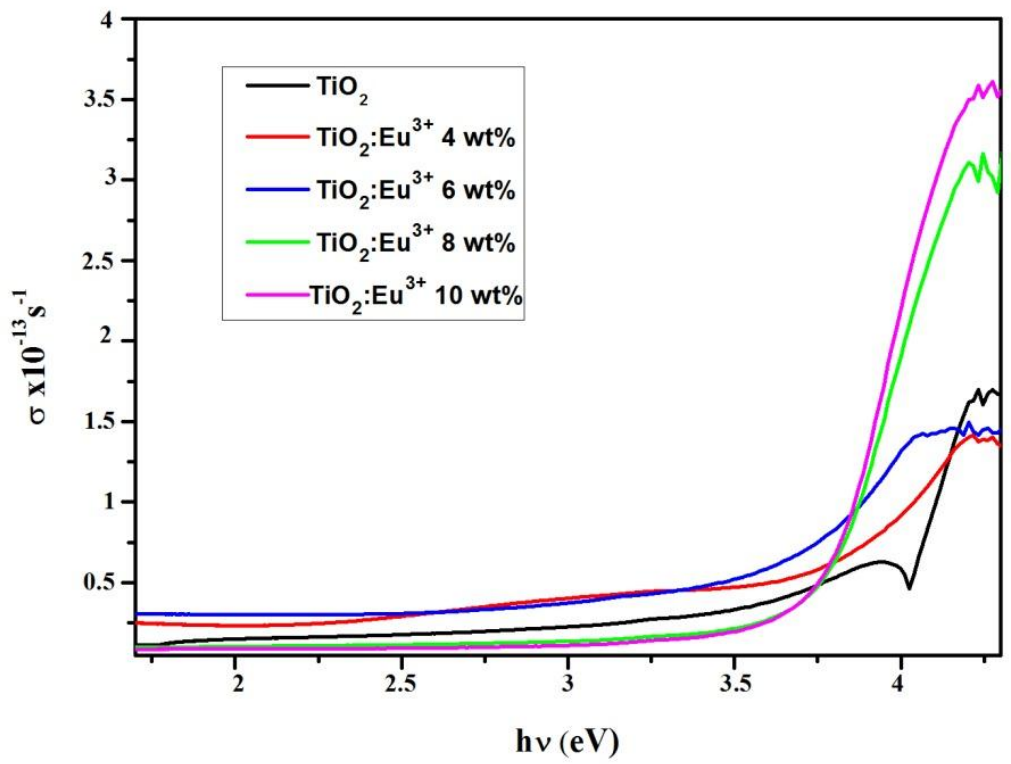

FIG. 8. Optical conductivity of undoped and $\mathrm{TiO}_{2}: \mathrm{Eu}^{3+}$ thin films.

\section{ii. Electrical studies:}

To ascertain the electrical properties of the undoped and $\mathrm{TiO}_{2}: \mathrm{Eu}^{3+}$ films, the four-points probe method was used. The sheet resistance $\left(\mathrm{R}_{\mathrm{sh}}\right)$ of the films were calculated using the following $\mathrm{Eq}(8):{ }^{32}$

$R_{s h}=\frac{\pi}{\ln 2} \cdot \frac{V}{I}$

Where $\mathrm{v}$ is measurement voltage and I is applied current.

The electrical conductivity was measured for various $\mathrm{Eu}^{3+}$ concentrations by the following Expression (9): ${ }^{33}$

$\sigma_{e l}=\frac{1}{d \cdot R_{S H}}$

Where $d$ is the films thickness. In Figure 9, we have reported the variation of the electrical conductivity in the undoped and $\mathrm{TiO}_{2}: \mathrm{Eu}^{3+}$ thin films as a function of $\mathrm{Eu}^{3+}$ doping ratio. As clearly see, the increase in the amount of 
$\mathrm{Eu}^{3+}$ causes a rapid increase in electrical conductivity reach it is a maximum conductivity value $3.01 \times 10^{-2}(\Omega . \mathrm{cm})^{-1}$ at high doping level $10 \mathrm{wt} \%$. This related to increase the carrier concentration with increase of $\mathrm{Eu}^{3+}$ atoms percentage in $\mathrm{TiO}_{2}$ thin films led to substitution of $\mathrm{Eu}^{3+}$ ions with oxygen ions. This substitution lead to reduce the potential barriers, resistance and promoted the conduction band. This behavior, already reported in the literature for the case of $\mathrm{Fe}$ doped $\mathrm{TiO}_{2}{ }^{34}$ and for Ni-doped $\mathrm{ZnO}$ thin films. ${ }^{35}$

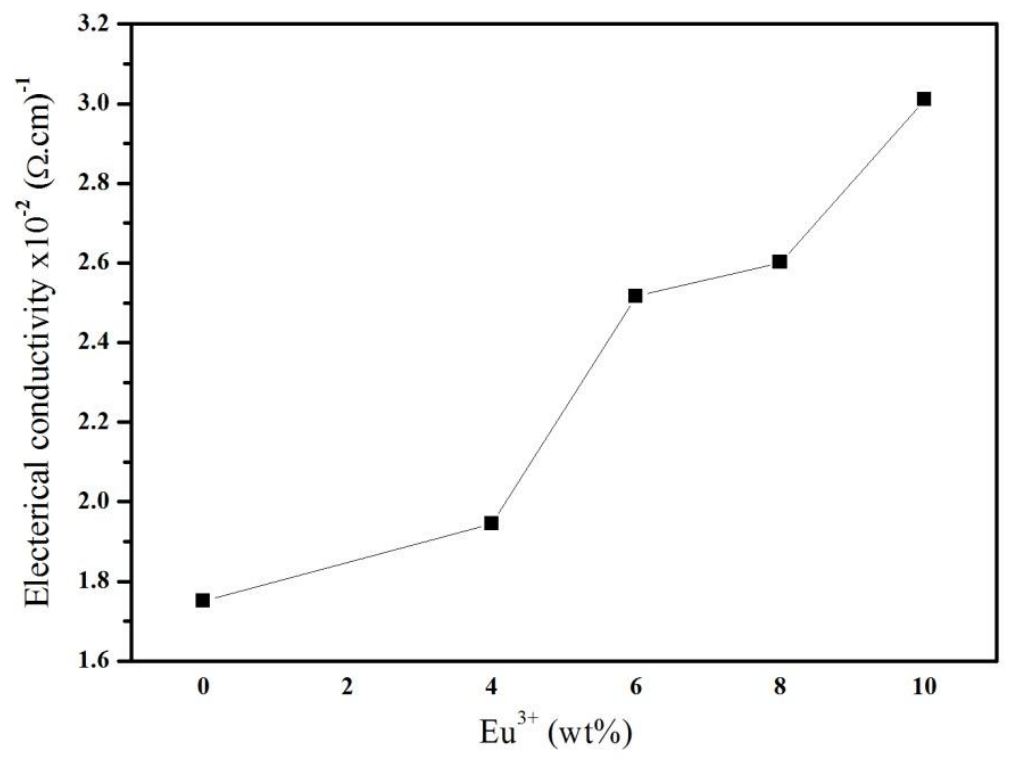

FIG. 9. Effect of doping concentration on electrical conductivity of undoped and $\mathrm{TiO}_{2}: \mathrm{Eu}^{3+}$ thin films.

\section{iii. Structural studies:}

$\mathrm{X}$-ray diffraction pattern has been used to study the phase identification and structural properties of the prepared films. Figures 10 indicate the XRD arrangements of undoped and $\mathrm{TiO}_{2}$ : $\mathrm{Eu}^{3+}$ thin films with distinct doping concentration. Undoped $\mathrm{TiO}_{2}$ thin film illustrates is combination of anatase 
and rutile phase is mostly the anatase with some amounts of rutile phase which is presented in figure (10 -a). $\mathrm{In} \mathrm{TiO}_{2}: \mathrm{Eu}^{3+}$ samples anatase phase is kinetically favored over rutile, which is thermodynamically stable phase. From the XRD pattern figure $(10-b)$, it is observed that the $4 \mathrm{wt} \% \mathrm{TiO}_{2}$ : $\mathrm{Eu}^{3+}$ thin films have preferential orientation along (1 111$)$ and (211) planes which corresponds to tetragonal crystal structure of anatase phase . These results is in good agreement with standard data JCPDS file and literature. ${ }^{36}$ There is not any diffraction peak found in the sample related to $\mathrm{Eu}^{3+}$ probably due to the small amount of $\mathrm{Eu}^{3+}$ doping. For $6 \mathrm{wt} \%$ and $8 \mathrm{wt} \%$ samples the (111) peaks corresponding to the anatase phase in general decreases in the intensity attributed to the reduction of crystalline quality. Additional peaks were also observed at $\mathrm{Eu}^{3+} 8 \mathrm{wt} \%$ sample along (101) and (110). Further increase of $\mathrm{Eu}^{3+}$ doping for $10 \mathrm{wt} \%$ sample the crystallization of $\mathrm{TiO}_{2}$ film might have decreased due to the deformation in the lattice at especially high $\mathrm{Eu}^{3+}$ doping ratio. 

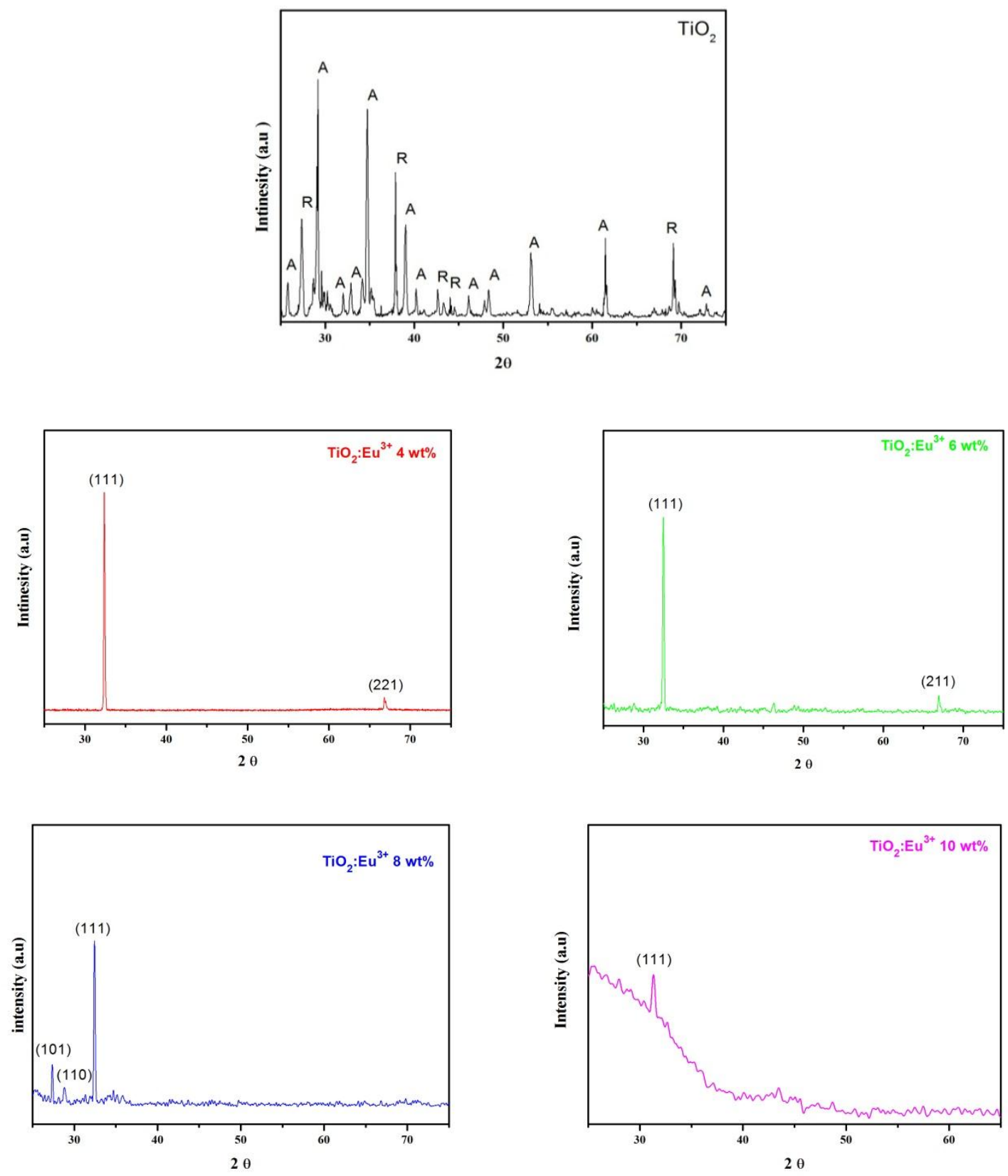

FIG. 10. The XRD patterns of undoped and $\mathrm{TiO}_{2}: \mathrm{Eu}^{3+}$ thin films.

The average crystallite size of the films are evaluated using DebyeScherrer's formula as expressed below (10): ${ }^{37}$

crystallite size $D=\frac{K \lambda}{\beta \cos \theta}$ 
Here, $\mathrm{k}=0.9, \lambda, \beta$ and $\theta$ are shape factor, $\mathrm{X}$-ray wavelength of $\mathrm{Cu} \mathrm{K} \alpha$, full width at half maximum (FWHM) and Bragg angle, respectively. Table III shown that the average crystallite size decreased linearly by the increasing of the concentration of $\mathrm{Eu}^{3+}$. This can be attributed to the kinetic segregation of dopants and produce of nucleation centers on the surface at higher doping amount. Arunachalam et al( 2015). found similar result for $\mathrm{TiO}_{2}$ : $\mathrm{Zn}$ thin films prepared by spray pyrolysis method. ${ }^{38}$

Dislocations are imperfection in a crystal related with the misfit of the lattice in one part of the crystal with the other part. Dislocation density $(\delta)$ that describes the dislocation lines per unit volume of the crystals. The values ' $\delta$ ' were calculated from the crystallite size (D) using the relation(11) below ${ }^{39}$ and values are presented at Table III:

$\delta=\frac{1}{D^{2}}$

The calculated dislocation density shows that as the $\mathrm{Eu}^{3+}$ content enhance, the dislocation density which can be credited to the large discrepancy of ionic radii of $\mathrm{Eu}^{+3}$ and $\mathrm{Ti}^{+4}\left(\mathrm{Eu}^{+3}=0.95 \AA\right.$ and $\left.\mathrm{Ti}^{+4}=00.68 \AA\right)$. Therefore, the lattice constants a and c values fluctuate around a mean value of $\mathrm{TiO}_{2}$ single crystals $(\mathrm{a}=3.785 \mathrm{~nm}$ and $\mathrm{c}=9.513 \mathrm{~nm})$. The degree of the crystal lattice distortion is established using the formula (12): ${ }^{27}$

$R=\frac{2 a \sqrt{\frac{2}{3}}}{c}$

The calculated results are listed in Table III. It is evident that the crystal lattice distortion rises with doping, as we predicated because of insertion of $\mathrm{Eu}^{+3}$ ions into the $\mathrm{TiO}_{2}$ structure. Similar results were observed by $\mathrm{Pal}$.et 
$\mathrm{al}^{39}$ The microstrain $(\varepsilon)$ of the prepared un doped and $\mathrm{TiO}_{2}: \mathrm{Eu}^{3+}$ thin films can be calculated from the relation $(13):^{40}$

$\varepsilon=\frac{\beta \cos \theta}{4}$

It is observed that microstrain decrease with increasing doping concentration, which imply decrease in defect, is due to the motion of the interstitial atoms from their grain boundary to the crystals.

The number of crystallites per unit surface area can be calculated using the following $\mathrm{Eq}(14):^{40}$

$N=\frac{d}{D^{3}}$

Where $\mathrm{d}$ is the film thickness. Table III summarizes crystallites per unit area along diffraction planes for films. For high doping concentration $10 \mathrm{wt} \%$, crystallites per unit area rises, which show dense surface.

Table III. Micro structural parameters of the undoped, and $\mathrm{TiO}_{2}: \mathrm{Eu}^{3+}$ films

\begin{tabular}{|c|c|c|c|c|c|}
\hline Sample & $\begin{array}{c}\text { Average } \\
\text { crystallites } \\
\text { size }(\mathbf{n m})\end{array}$ & $\begin{array}{c}\text { lattice } \\
\text { distortion } \\
\text { degree } \mathbf{R}\end{array}$ & $\begin{array}{c}\text { dislocation } \\
\text { density } \\
\text { (lines/m² }^{2} \text { ) } \\
\mathbf{x 1 0}\end{array}$ & $\begin{array}{l}\text { Microstrain } \\
\quad\left(\varepsilon \times 10^{-3}\right)\end{array}$ & $\begin{array}{l}\text { Cells number } \\
\left(\mathrm{N} \times 10^{15} / \mathrm{m}^{-2}\right)\end{array}$ \\
\hline $\mathrm{TiO}_{2}$ & 56.70 & 0.50 & 3.11 & 5.81 & 53 \\
\hline $\mathrm{TiO}_{2}: \mathrm{Eu} 4 \mathrm{wt} \%$ & 12.68 & 0.55 & 6.22 & 4.25 & 60 \\
\hline $\mathrm{TiO}_{2}: \mathrm{Eu} 6 \mathrm{wt} \%$ & 9.81 & 0.59 & 10.39 & 3.97 & 130 \\
\hline $\mathrm{TiO}_{2}: \mathrm{Eu} 8 \mathrm{wt} \%$ & 8.95 & 0.65 & 12.48 & 3.75 & 163 \\
\hline $\mathrm{TiO}_{2}: \mathrm{Eu} 10 \mathrm{wt} \%$ & 6.94 & 0.66 & 20.76 & 3.36 & 383 \\
\hline
\end{tabular}




\section{iv. Surface Morphology studies:}

Figure (11) (a-f) presents the SEM images of the prepared undoped and $\mathrm{TiO}_{2}: \mathrm{Eu}^{3+}$ thin films. The surface morphology for all samples is similar. SEM images exhibit that the films have the irregular shaped aggregates and spherical particles in small diameter cover the substrate surface uniformly. The average grain size values for undoped and (4, 6,8 and $10 \mathrm{wt} \%) \mathrm{TiO}_{2}$ : $\mathrm{Eu}^{3+}$ thin films are found $82.5,68.6,61.2,57.7,51.1 \mathrm{~nm}$, respectively. It can observed that with the addition of $\mathrm{Eu}^{3+}$ atoms the grain size reduced significantly. The reduction of the grain size can be attributed to inhibition of grain growth induced by dissolution of $\mathrm{Eu}^{3+}$ ions into $\mathrm{TiO}_{2}$ lattice. Moreover, dragging effect between $\mathrm{Eu}^{3+}$ ions and the grain boundaries can be responsible for grain size reduction. This is in well accordance with result observed by Hsiao et al(20). ${ }^{41}$ 

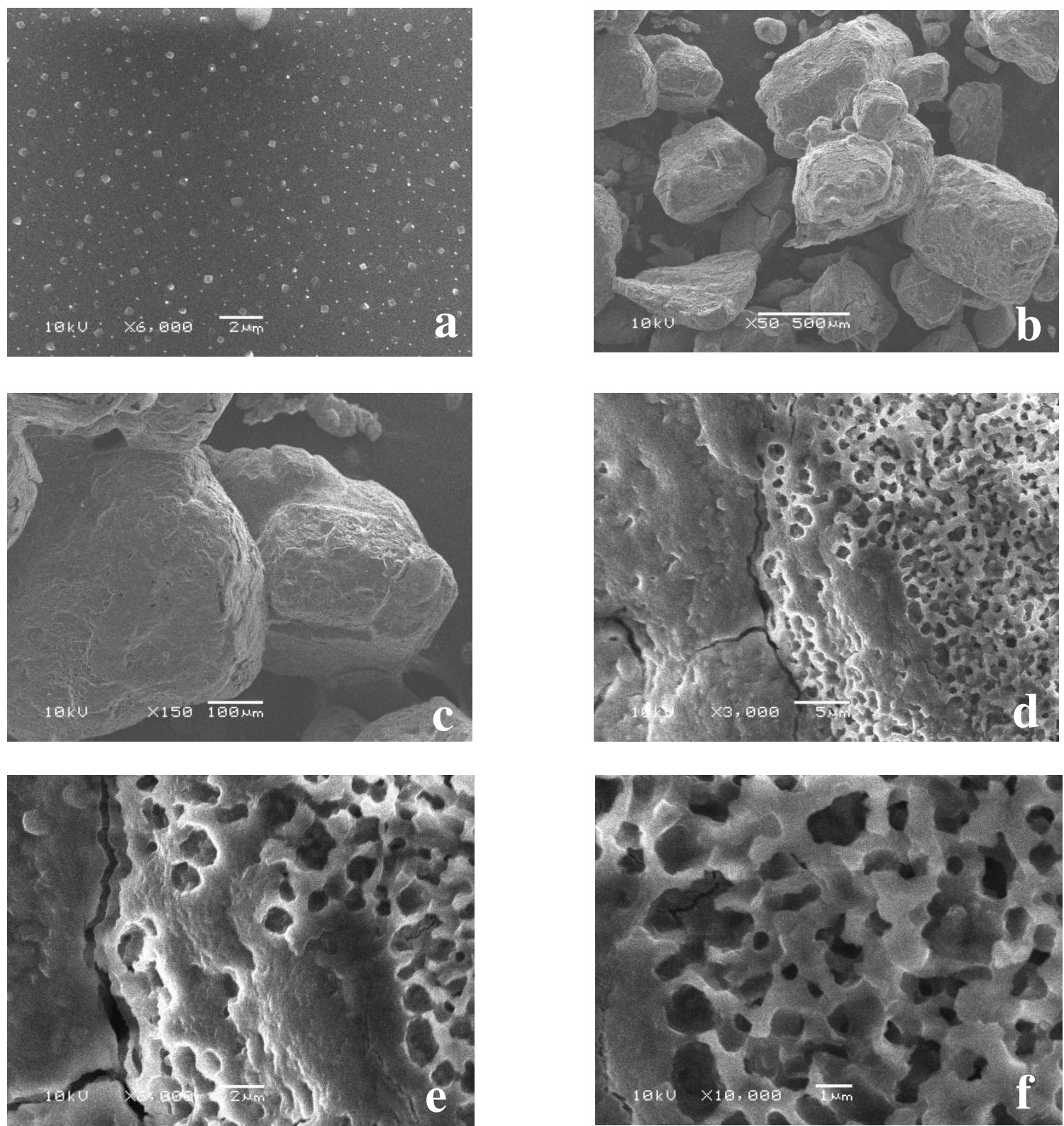

FIG. 11. SEM images of ( a ) undoped and ( b-f ) $\mathrm{TiO}_{2}: \mathrm{Eu}^{3+}$ thin films. 


\section{v. Photocatalytic Studies:}

The photocatalytic activity of all prepared films is measuring the degradation of methylene blue solution (MB) with different concentration of UV light irradiation multiple times. The concentration of methylene blue is in a linear relationship with absorbance as shown in Figure 12.

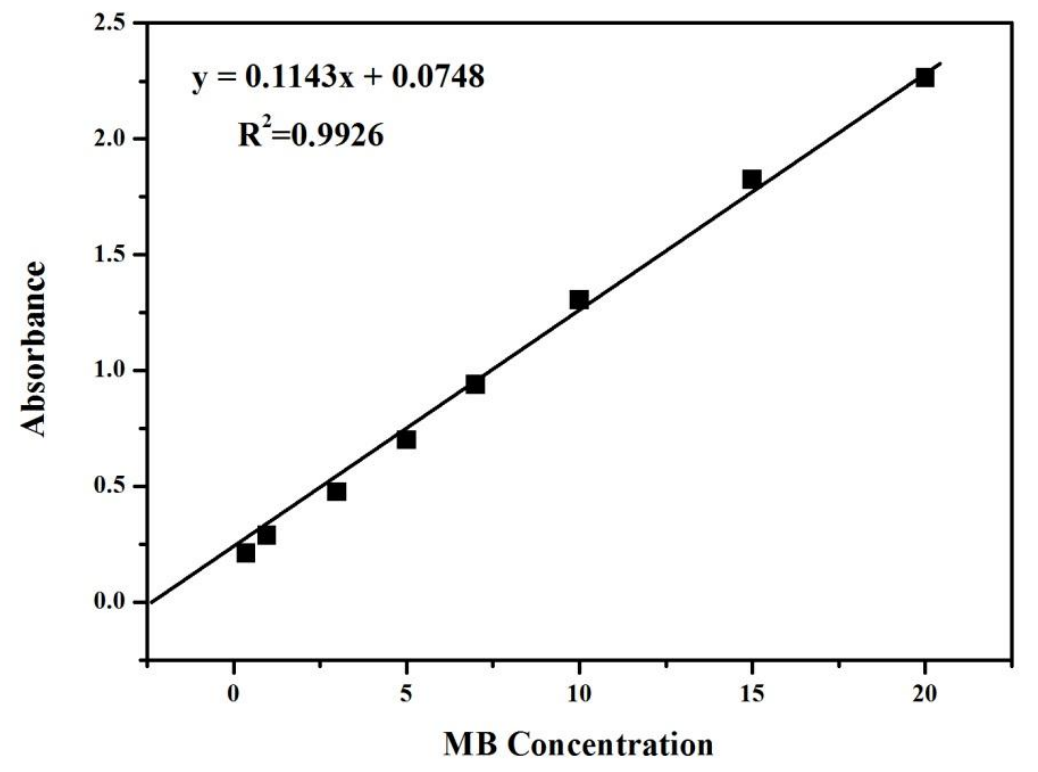

FIG. 12. MB concentration curve with absorbance.

The photocatalytic decomposition of $\mathrm{MB}$ using $\mathrm{TiO}_{2}$ and $\mathrm{TiO}_{2}: \mathrm{Eu}^{3+}$ thin films under UV light versus irradiation period is illustrated in Figure 13. 


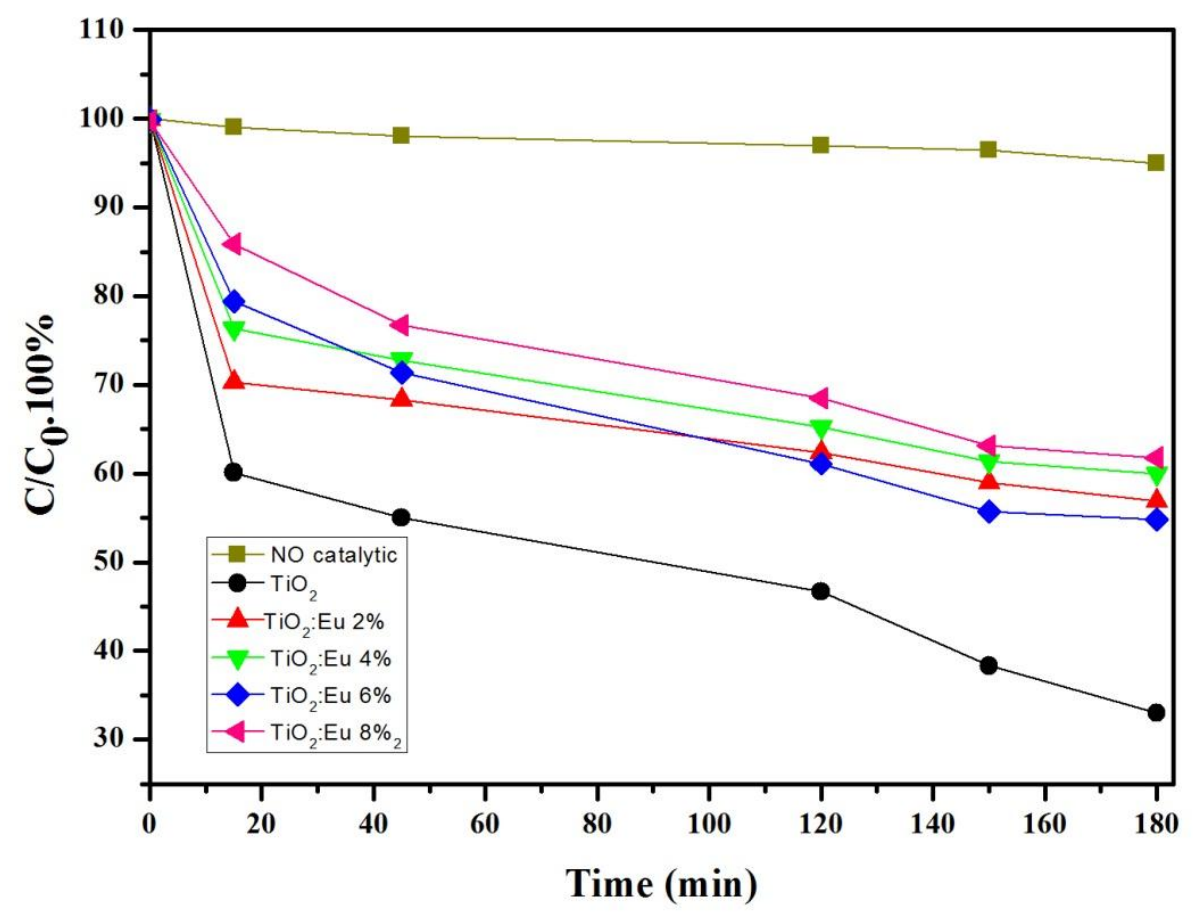

FIG. 13. Degradation of $\mathrm{MB}$ using undoped and $\mathrm{TiO}_{2}: \mathrm{Eu}^{3+}$ thin films under UV light as a function of time.

Figure 13 shows that $\mathrm{MB}$ dye decays constantly throughout the irradiation of samples. It is found that $\mathrm{Eu}^{3+}$ added in $\mathrm{TiO}_{2}$ exhibit significantly enhanced in photocatalytic activity reaction under UV irradiation compared with undoped $\mathrm{TiO}_{2}$. The photocatalytic activity is influenced by many factors such as crystal structure, defects and particle size, impurity, thickness, and surface area. $\mathrm{Eu}^{3+}$ doping provide electron traps to restrict recombination of photo-excited electron-hole pairs and produces impurity levels between conduction band and valence band of $\mathrm{TiO}_{2}$ lead to change in absorption characteristics of $\mathrm{TiO}_{2}$. High doping films $10 \mathrm{wt} \%$ is appeared to give maximum performance because of small crystal size of anatase phase, large value of $\mathrm{OH}$ radicals and $\mathrm{O}_{2}$ on $\mathrm{TiO}_{2}$ surfaces. ${ }^{42}$

Degradation efficiency $(\eta)$ of photocatalyst was calculated as follows $(15):{ }^{25}$ 
$\eta=\frac{c_{o}-c_{i}}{c_{0}} \times 100 \%$

Where Co initial concentration, Ci sample concentration. As shown in figure 14 the better results were observed at high doping concentration of $\mathrm{TiO}_{2}$ : $\mathrm{Eu}^{3+}$ thin films. The variation in $\eta$ values were attributed to the differences in physical properties of the films. The degradation efficiency of UV light improves by growing amount of $\mathrm{Eu}^{3+}$ due to increase the e/h pair production and film width that increases the mass. Results suggest that $\mathrm{Eu}^{+3}$ ions doping in $\mathrm{TiO}_{2}$ thin films performs a vital role in the enhancement of photocatalytic efficiency under $\mathrm{UV}$ light. $\mathrm{Eu}^{+3}$ doped $\mathrm{TiO}_{2}$ thin films is highly promising materials for photovoltaic cells, visible light photo-catalysis, and other photonic devices.

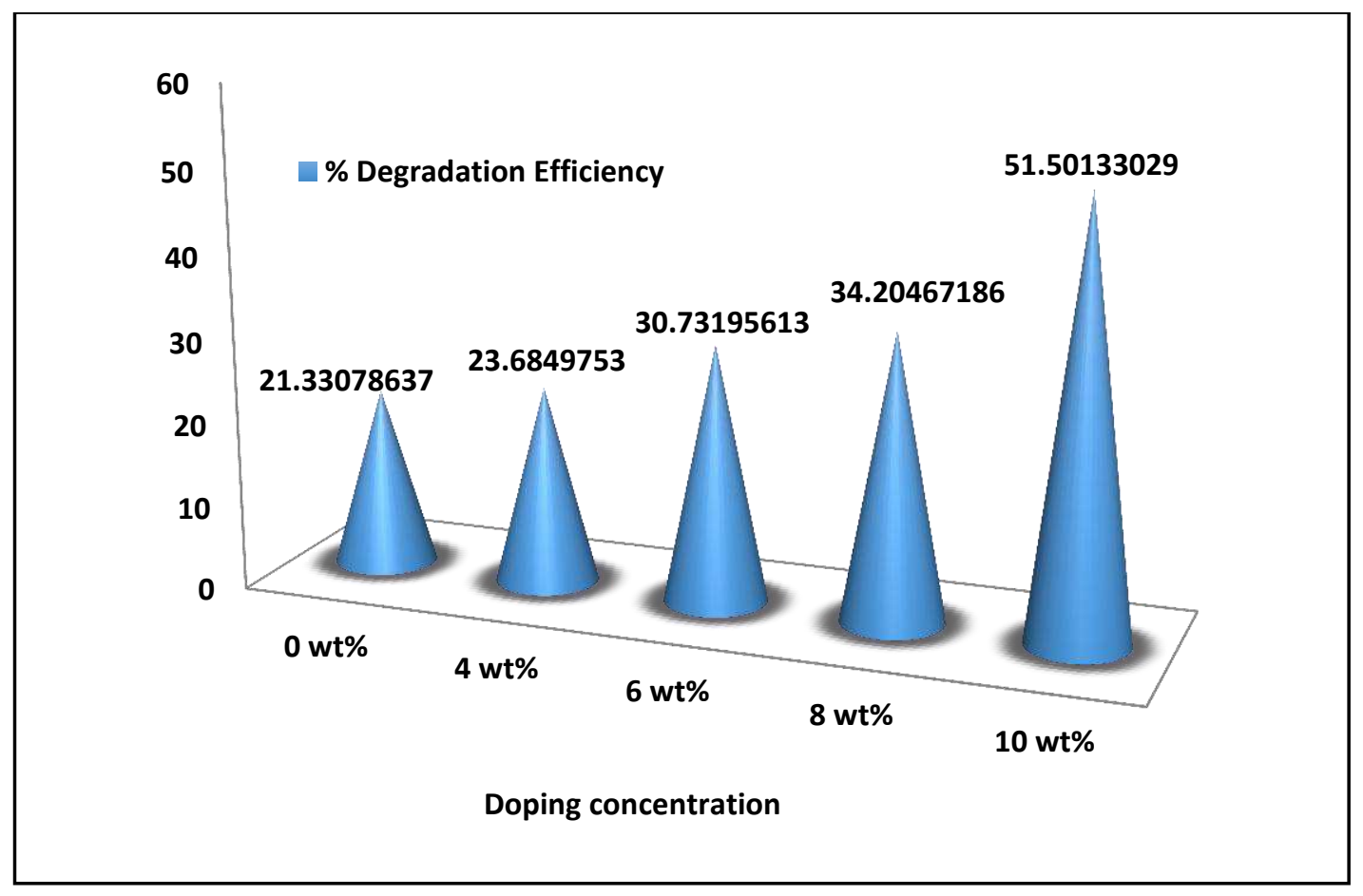

FIG. 14. Degradation efficiency undoped and $\mathrm{TiO}_{2}: \mathrm{Eu}^{3+}$ thin films under UV light. 


\section{Conclusion:}

In present article, the consequence of $\mathrm{Eu}^{3+}$ doped $\mathrm{TiO}_{2}$ thin films with varying $\mathrm{Eu}^{3+}$ concentrations deposited by Spray pyrolysis technique on glass substrates has been investigated. The fabricated $\mathrm{TiO}_{2}: \mathrm{Eu}^{3+}$ thin films show improvement in optical properties. The highest transmittance and lowest reflectance were observed at $10 \mathrm{wt} \% \mathrm{Eu}^{3+}$ content. The thickness of the samples increases from $97.13 \mathrm{~nm}$ to $128.25 \mathrm{~nm}$.. At the same time increasing the $\mathrm{Eu}^{+3}$ doping initially led to slight increase in the optical band gap which can be explained by growth defect, charge impurities, disorder at the grain boundary and Burstein Moss effect. Electrical properties have been estimated by four-point probe method it has been detected that maximum conductivity value $3.01 \times 10^{-2}(\Omega . \mathrm{cm})^{-1}$ at high doping level $10 \mathrm{wt} \%$. The XRD patterns revealed that $\mathrm{TiO}_{2}: \mathrm{Eu}^{3+}$ films show anatase phase with the tetragonal crystal structure and reduces the crystalline size by increasing $\mathrm{Eu}^{3+}$ concentration. In addition, dislocation density, lattice distortion degree, microstrain and cells number are also concluded.

SEM analysis show that the films have the irregular shaped particles in small diameter and the grain size decrease with doping concentration because of inhibition of grain growth and dragging effect. The photocatalytic activity of the doped samples for MB degradation under UV light irradiation was significantly improved by $\mathrm{Eu}^{3+}$ ratio. The increase in photocatalytic activity of the $\mathrm{TiO}_{2}$ : $\mathrm{Eu}^{3+}$ thin films is due reduction of crystallite size, improvement of film thickness and avoid the photo-excited electron-hole pairs recombination. 


\section{Declarations:}

\section{Availability of data and materials:}

The data that support the findings of this study are available from the corresponding author upon reasonable request.

\section{Competing interests:}

The author declares that there is no conflict of interest regarding the publication of this paper.

\section{Funding:}

Not applicable.

\section{Author's contributions:}

Not applicable.

\section{Acknowledgements:}

The authors would like to acknowledge university of Hail for their device and help.

\section{References:}

1- Camps,i., Borlaf,M., Colomer, M.T., Moreno,R., Duta,L., Nita,C., Perez del Pino,A., Logofatu,C., Serna ,R., and Gyorgy, E.,"Structureproperty relationships for $\mathrm{Eu}$ doped $\mathrm{TiO} 2$ thin films grown by laser assisted technique from colloidal sols" RSC Advances 7,3764337653(2017).

2- Bai,J. and Zhou,B.," Titanium Dioxide Nanomaterials for Sensor Applications"Chem.Rev114,10131-101176(2014).

3- Zhang,Q., and Cao,G.," Nanostructured photoelectrodes for dyesensitized solar cells" Nano Today 6,91-109(2011). 
4- Leostean,C.,Stefan,M.,O.Pana, O.P,A.I.Cadis,A.L, Suciu, R.C.,Silipas, T.D,E., and Gautron,E.,"Properties of $\mathrm{Eu}$ doped $\mathrm{TiO}_{2}$ nanoparticles prepared by using organic additives" J. Alloys Compd 575, 29-39(2013).

5- $\quad \mathrm{Hu}, \mathrm{B}$., and Liu, B., "Dye-sensitized solar cells fabricated by the TiO nanostructural materials 2 synthesized by electrospray and hydrothermal posttreatment" Appl Surf Sci 358, 412-417 (2015).

6- Kenyon, A. J. "Recent developments in rare-earth doped materials for optoelectronics" Prog. Quantum Electron 26 (4-5), 225-284 (2002).

7- Ozturk,B., and Soylu, G.S.P.," Promoting role of transition metal oxide on ZnTiO3-TiO2 nanocomposites for the photocatalytic activity under solar light irradiation" Ceram. Int 42, 11184-11192(2016).

8- Cacciotti,I., Bianco,A., Pezzotti,G., and G. Gusmano, "Synthesis, thermal behaviour and luminescence properties of rare earth-doped titania nano fibers " Chem Eng J 166(2), 751-764( 2011).

9- Hwang,D.W., Lee, J. S. , Li, W. and Oh, S. H. "Electronic band structure and photocatalytic activity of $\mathrm{Ln}_{2} \mathrm{Ti}_{2} \mathrm{O}_{7}(\mathrm{Ln}=\mathrm{La}, \mathrm{Pr}, \mathrm{Nd}) " J$. Phys. Chem. B 107( 21), 4963-4970( 2003).

10- Adrian kitai" princible of luminance, in luminance materials and application , Wiley (2008)P 292.

11- Zhu,C., Chunyan, L.v, Wang,C., Sha,Y., Li,D., Ma,X., and Yang, D., "Color-tunable electroluminescence from Eudoped TiO2/p+-Si heterostructured devices: engineering of energy transfer" Opt. Express 23( 3), 2819-2826 (2015).

12- Komaraiah,D., Radha,E., James,J., Kalarikkal, N.K.,J.Sivakumar,J., Ramana,M.V., Reddy and Sayanna, R." Effect of particle size and dopant concentration on the Raman and the photoluminescence spectra of $\mathrm{TiO}_{2}: \mathrm{Eu}^{3+}$ nanophosphor thin films" J. Lumin 211, 320-333(2019).

13- Shiba,K., Kataoka,T., and Tagay,M., "Preparation of Eu(III) acetylacetonate-doped well-defined titania particles with efficient photoluminescence properties" Royal.Chem. Soc 47, 1972-1980(2018).

14- Singh P, Kushal A and Kaur D.," Mn-doped ZnO nanocrystalline thin films prepared by ultrasonic spray pyrolysis" J. Alloy Compd 471, 11-15(2009). 
15- Wang, S., Wu ,x.,Qin, W., and Jiang,Z., " $\mathrm{TiO}_{2}$ films prepared by micro-plasma oxidation method for dye-sensitized solar cell" Electrochim. Acta 53(4),1883-1889(2007).

16- Al-shomar,S.M., and Alahmad ,W.R., , "Annealing temperature effect on structural, optical and photocatalytic $\mathrm{TiO}_{2}$ films preapared by solgel method used for solar cell " Dig J Nanomater Bios 14(3), $617-625(2019)$.

17- Oja, I., Mere, A., Krunks, M., Solterbeck, C. H., and Souni, M. E.," Properties of TiO2 films prepared by the spray pyrolysis method" Solid State Phenom 99, 259-264 ( 2004).

18- Zhao,J.,Duan,H.,.Ma,Z.,Liu,L.,andXie,E."Effect of temperature on the photoluminescence of $\mathrm{Eu}^{3+}$ dopedTiO ${ }_{2}$ nanofiber sprepared by electrospinning" J. Optoelectron .Adv.Mater10, 3029-3032(2008).

19- Chang,M., Song,Y., Sheng,Y., Chen,J., Guan, H., Shi,Z., Zhou,X., Zheng,K., and Zou,H.," Photoluminescence and photocatalysis properties of dual-functional $\mathrm{Eu}^{3+}$ doped anatase nanocrystals ",J.Phys.Chem.C 121,2369-2379(2017).

20- Alpha,M., and Daniel,T.O," Effect of Doping Concentration on the Electrical and Optical Properties of $\mathrm{Zn:} \mathrm{SnO}_{2}$, J. Appl. phys 7( 3 ), 38-44(2015).

21- Samson, D. O. and Makama, E. K. ,"Effect of Concentration on Morphological, Optical and Electrical Properties of Copper Doped Zinc Oxide Thin Films Deposited by Electrostatic Spray Pyrolysis (ESP) Technique" J. of Mater Sci. Rev 4,1-14 (2019).

22- Samarasekara,P., and Wijesinghe,U.,"Optical properties of spin coated $\mathrm{Cu}$ doped $\mathrm{ZnO}$ nanocompsite films" GESJ: Physics 2(14),41-50 (2015).

23- Hajjaji,A., Gaidi,M., Bessais,B., and M.A. El Khakani, M.A.," Effect of $\mathrm{Cr}$ incorporation on the structural and optoelectronic properties of $\mathrm{TiO}_{2}: \mathrm{Cr}$ deposited by means of a magnetron co-sputtering process" Appl. Surf. Sci 257(24), 10351-10357(2011).

24- Sönmezo glu,S., Arslan,A., Serin,T., and Serin,N., "The effects of film thickness on the optical properties of $\mathrm{TiO}_{2}-\mathrm{SnO}_{2}$ compound thin films" Phys. Scr. 84, 065602-065608 (2011). 
25- Alshomar,S.M ,"Investigation the effect of doping concentration in

Ruthenium-doped $\mathrm{TiO}_{2}$ thin films for solar cells and sensors applications" Mater. Res. Express7 (3), 036409 - 036420 (2020).

26- Yousif, A.A, Aadim,K.A., and Hamzah, N.A "Influence of Ag doping on Optical Properties of Nanocrystalline Titanium Dioxide prepared by PLD" J. Appl. Phys 8(5),50-56(2016).

27- Uzar,N., "Investigation of detailed physical properties and solar cell performances of various type rare earth elements doped $\mathrm{ZnO}$ thin films" J. Mater. Sci.: Mater. Electron 12, 10471-10479(2018).

28- Hu,L., Yoko,T., Kozuka,H., and Sakka,S., "Effect of solvent on properties of sol-gel derived $\mathrm{TiO}_{2}$ coating film" Thin solid films 219 (1-2), 18-23(1992).

29- Kaleji, B.K., Sarraf-Mamoorya,R., and Akira Fujishima,A., "Influence of $\mathrm{Nb}$ Dopant on the Structural and Optical Properties of Nanocrystalline TiO2 Thin Films" Mater. Chem. Phys 132(1), 210215(2012).

30- Ayieko, C. O., Musembi, R. J., Waita1, S. M., Aduda, B. O. and Jain, P. K. , "Structural and Optical Characterization of Nitrogen-doped $\mathrm{TiO}_{2}$ Thin Films Deposited by Spray Pyrolysis on Fluorine Doped Tin Oxide (FTO) Coated Glass Slides" Int. J. Energy ENG 2(3), 67-72 (2012).

31- AlFaify, S., Harith, L., Manthrammel, M.A., Ganesha,V., Chandekar, V.K., Shaikhd, S.S., and Shkir,M., "Fabrication and characterization of Sn:CdS films for optical-nonlinearlimiting applications"Opt. Laser Technol 126, 106-122(2020).

32- Benramache, S., Aoun, Y., Lakel,S., Benhaoua,B., and Torchi,C., "The calculate of optical gap energy and urbach energy of $\mathrm{Ni}_{1^{-}} \mathrm{Co}_{\mathrm{x}} \mathrm{O}$ thin films" Ind. Acad. Sci 44,26-31(2019).

33- Bally, A. R., Korobeinikova, E. N., Schmid, P. E., L'evy, F., and Bussy, F., "Structural and electrical properties of Fe-doped $\mathrm{TiO}_{2}$ thin films" J. Phys. D: Appl. Phys. 31, 1149-1154(1998).

34- Herissi,L., Hadjeris,L., Aida, M.S., Azizi, S., Hafdallah,A., and Ferdi,A., "Ni-Doped ZnO Thin Films Deposited by Pneumatic Spray Pyrolysis" Nano Hybrid. Comp. 27, 21-29(2019). 
35- Franco, L. M. , Zambrano, G., and Gómez, M. E., "Photocatalytic activity of nitrogen-doped and undoped titanium dioxide sputtered thin films" Superficies y vacío25(3), 161-165( 2012).

36- Mohammed,A.S., Kafi, D. K., Ramizy, A., Abdulhadi, O. O., and Hasan, S. F., "Nanocrystalline Ce-doped Cde thin films synthesis by spray pyrolysis method for solar cell application" J. Ovonic Res 15(1), 37 42(2019).

37- Arunachalam,A., Dhanapandian, S., Manoharan, C., and Sivakumar, G., "Physical properties of $\mathrm{Zn}$ doped $\mathrm{TiO}_{2}$ thin films with spray pyrolysis technique and its effects in antibacterial activity" Spectrochim. Acta A 138, 105-112(2015).

38- Ravidhas , C., Anitha , B., Moses Ezhil Raj , A., K. Ravichandran , K., Sabari Girisun , T. C., Mahalakshmi , K., Saravanakumar , K. and Sanjeeviraja,C., "Effect of nitrogen doped titanium dioxide $\left(\mathrm{N}-\mathrm{TiO}_{2}\right)$ thin films by jet nebulizer spray technique suitable for photoconductive study" J Mater Sci: Mater Electron 26(6), 3573-3582 (1015).

39- Pal, M., Pal,U., Gracia, J.M., Jiménez,Y., and Pérez-Rodríguez, F., "Effects of crystallization and dopant concentration on the emission behavior of $\mathrm{TiO}_{2}$ : Eu nanophosphors" Nanoscale Res. Lett. 7(1), 2-12 (2012).

40- Vidhy,R., Sankareswari1,M., and Neyvasagam, k.,"Effect of annealing temperature on structural and optical properties of $\mathrm{CU}-\mathrm{TIO}_{2}$ thin films" Int. j. tech. Res. Appl 37,42-46(2016).

41- Hsiao,R.C., Arul,N.S., Mangalaraj,D., and Juang ,R.S., "Influence of $\mathrm{Eu}^{3+}$ doping on the degradation property of $\mathrm{TiO}_{2}$ nanostructures " J. Opto. Adv. Mater 12( 2), 193 - 198(2010).

42- Sangchay,W., Sikong,L., and Kooptarnond, K., "The Photocatalytic and Antibacterial Activity of Cu-Doped $\mathrm{TiO}_{2}$ Thin Films" Walailak J Sci \& Tech10(1), 19-27(2013). 
Figures
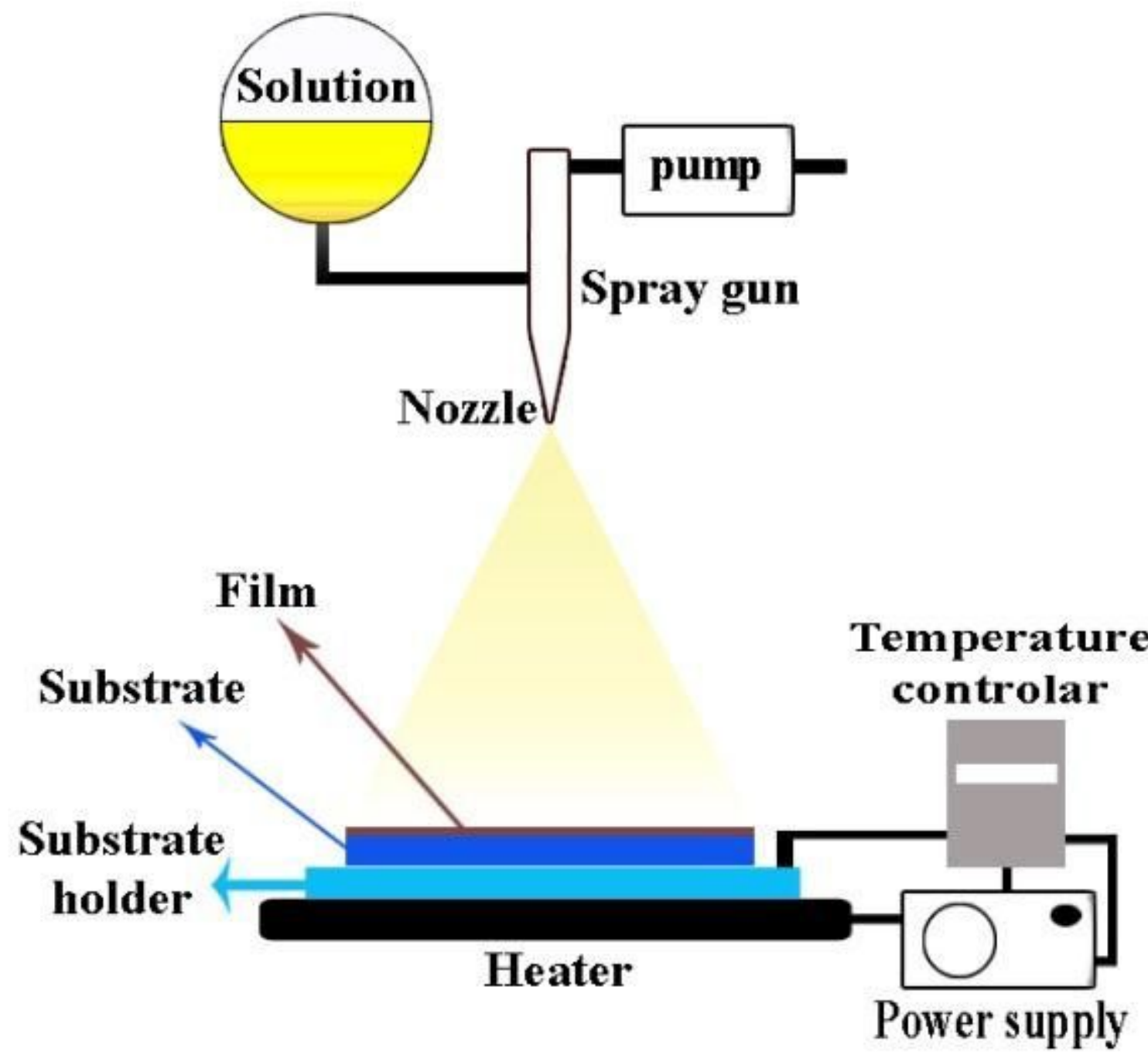

Figure 1

spray pyrolysis set up. 


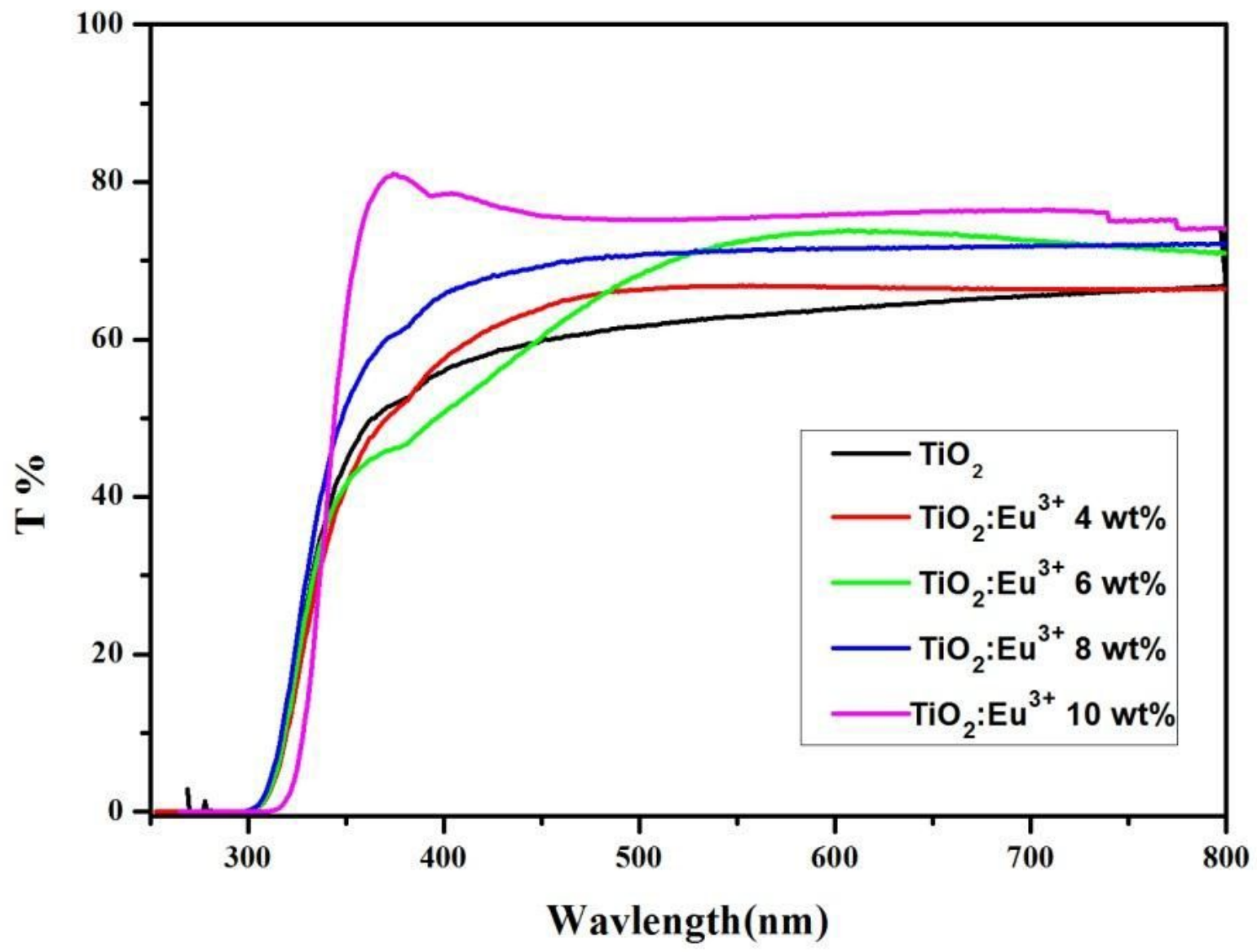

Figure 2

Transmission spectra of undoped and TiO2: Eu3+ thin films. 


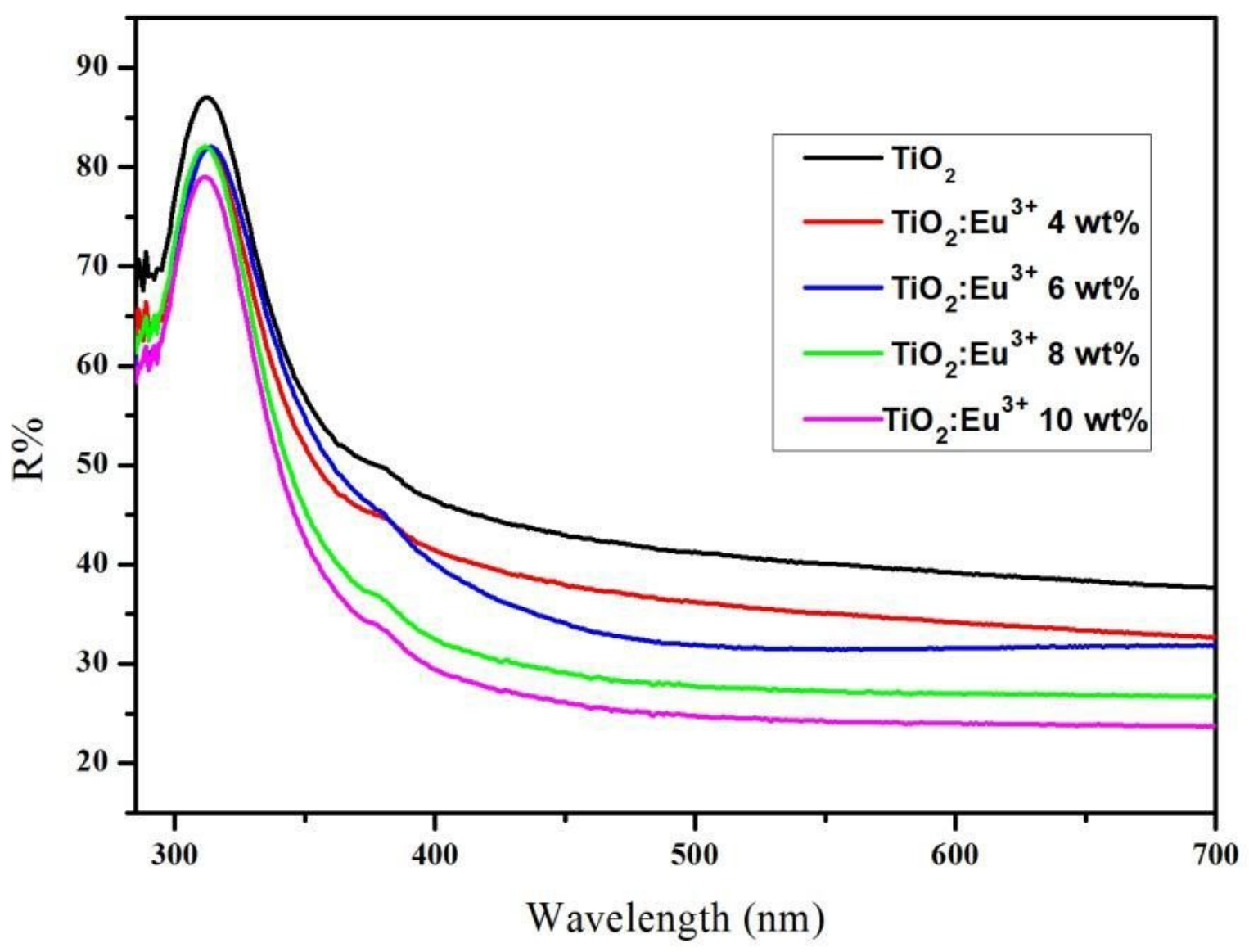

Figure 3

Reflectance spectra of undoped and TiO2: Eu3+ thin films. 


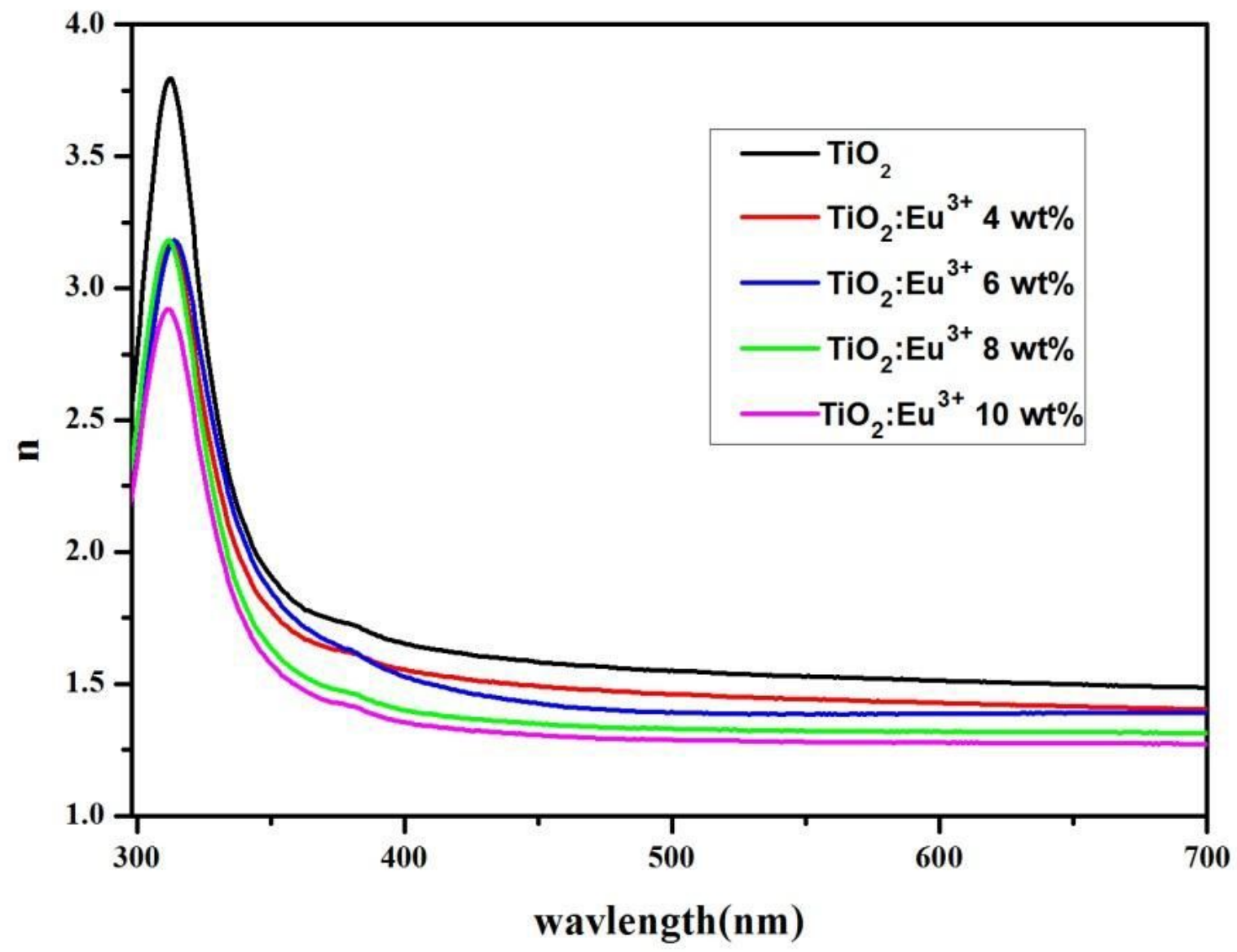

Figure 4

Effect of doping concentration on refractive index of undoped and TiO2: Eu3+ thin films. 


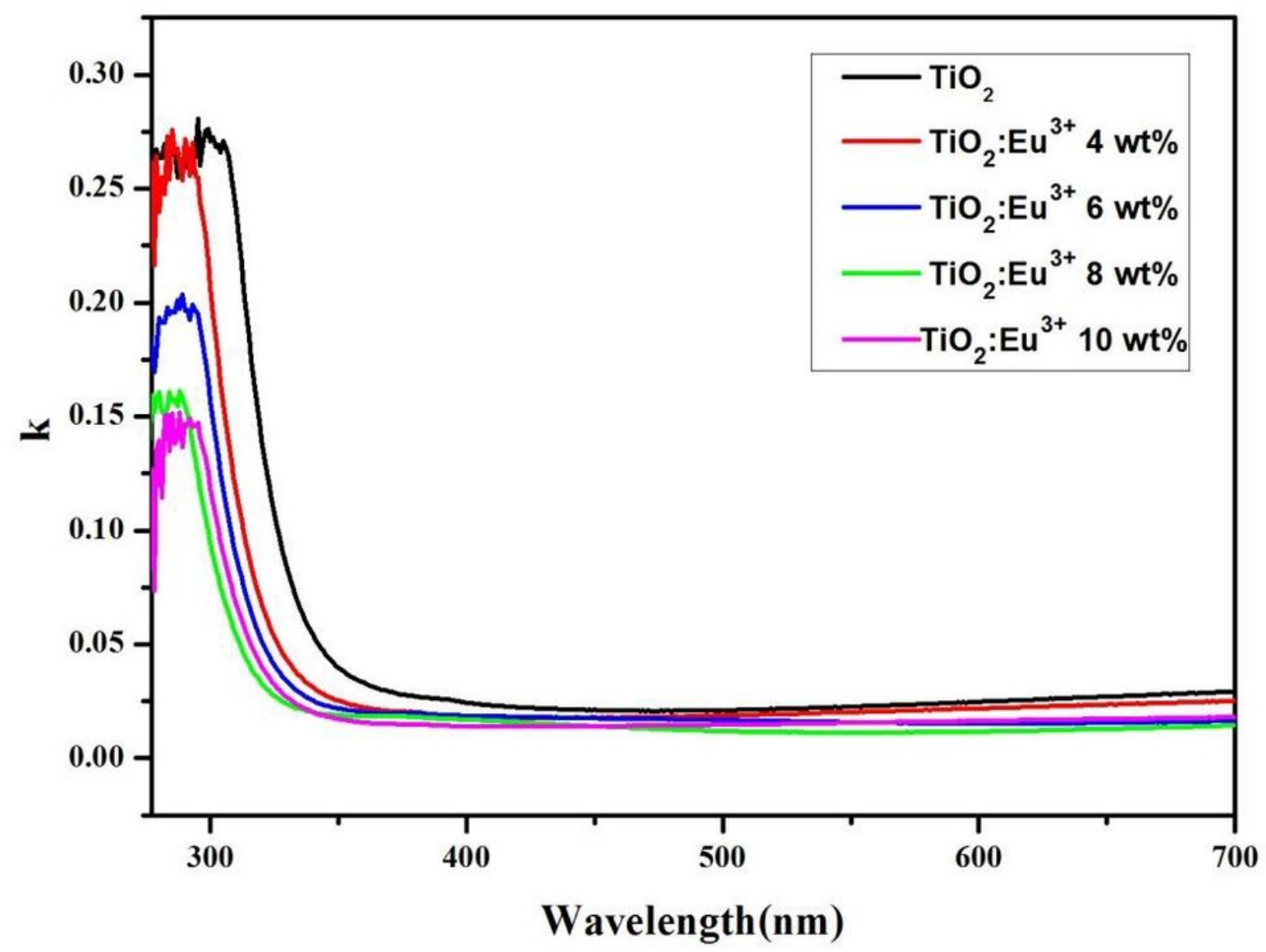

Figure 5

Effect of doping concentration on extinction coefficient of undoped and TiO2: Eu3+ thin films. 


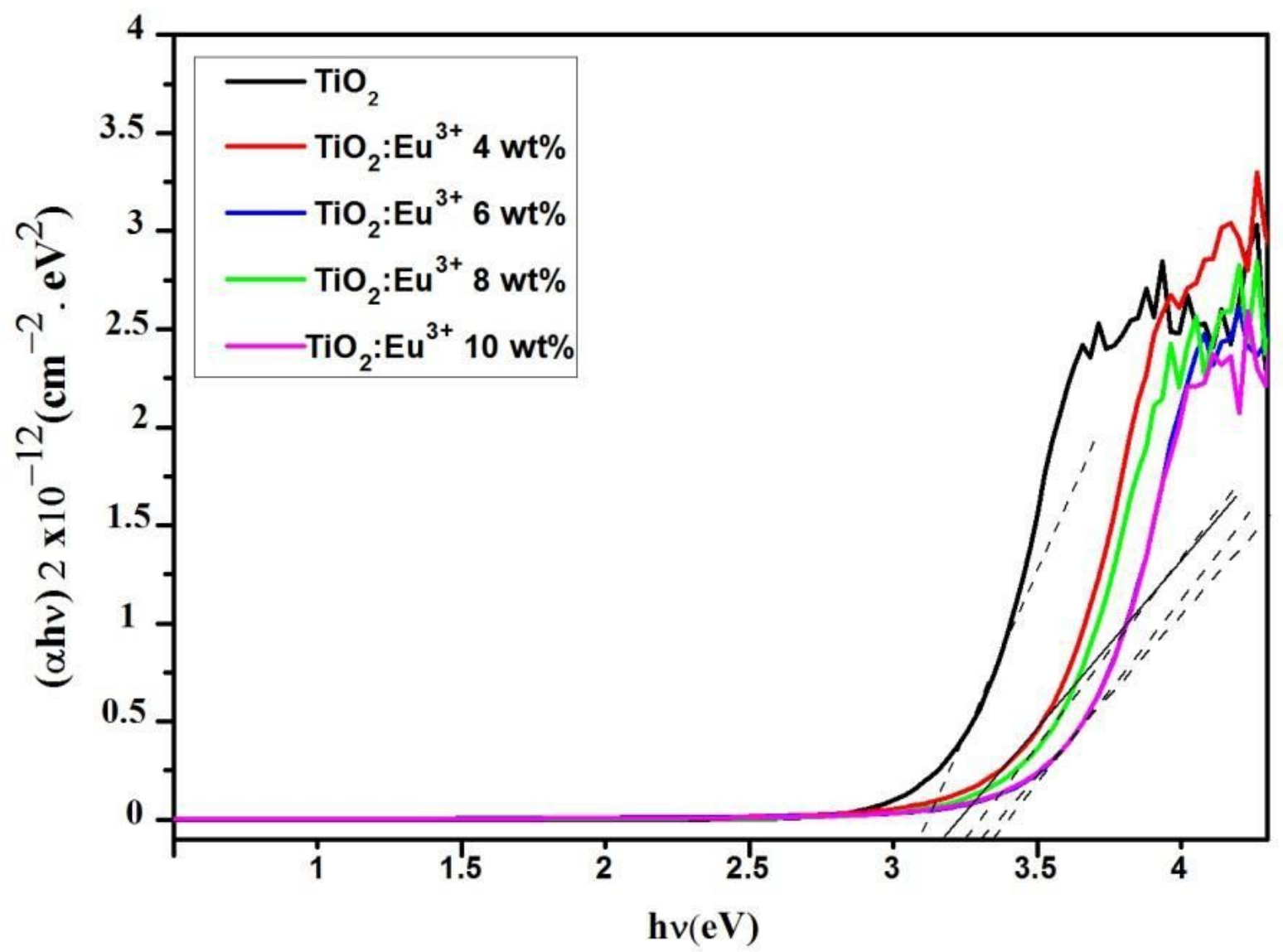

Figure 6

Direct band gap plot of undoped and TiO2: Eu3+ thin films. 


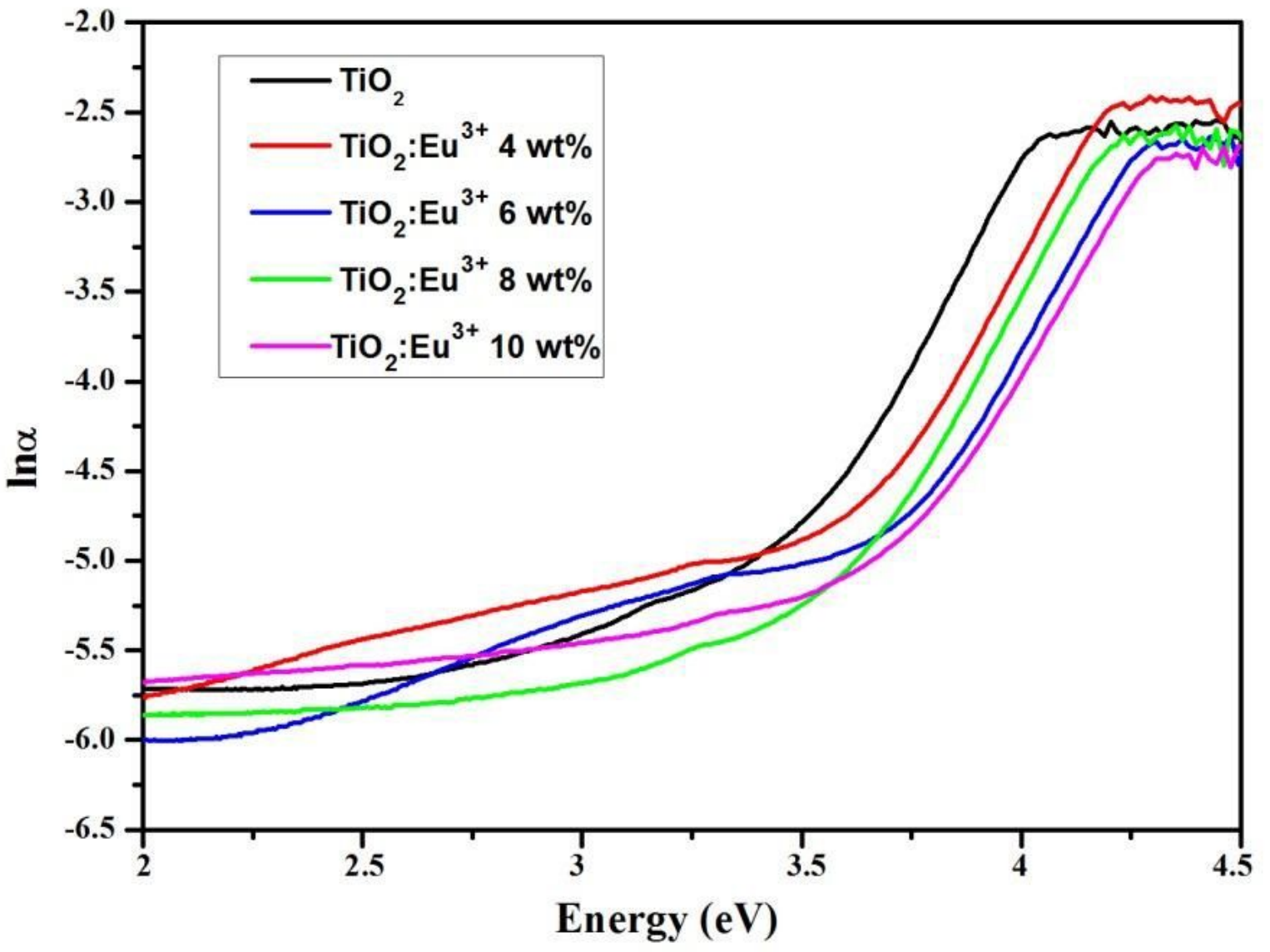

Figure 7

Urbach plot of undoped and TiO2: Eu3+ thin films. 


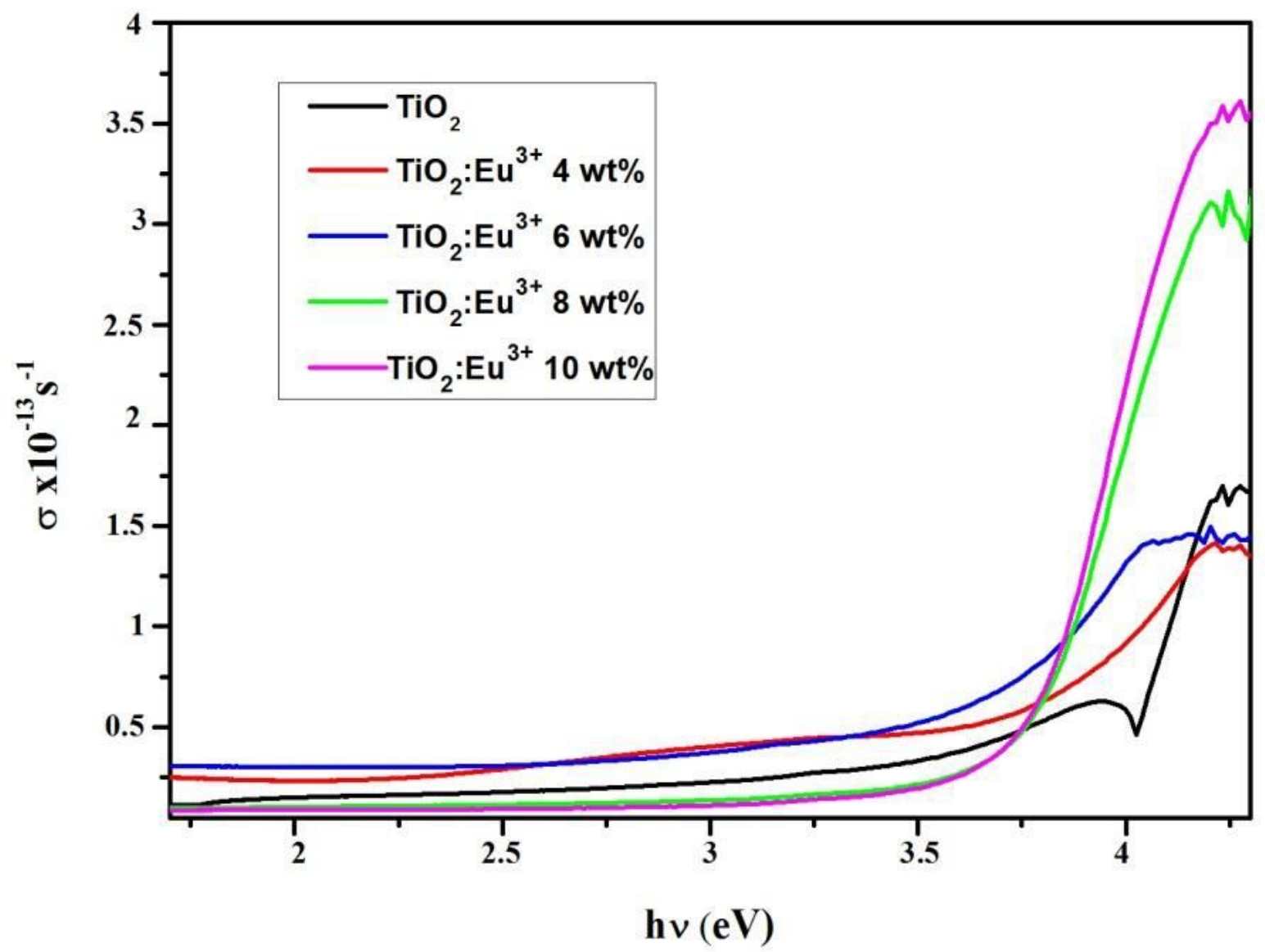

Figure 8

Optical conductivity of undoped and TiO2: Eu3+ thin films. 


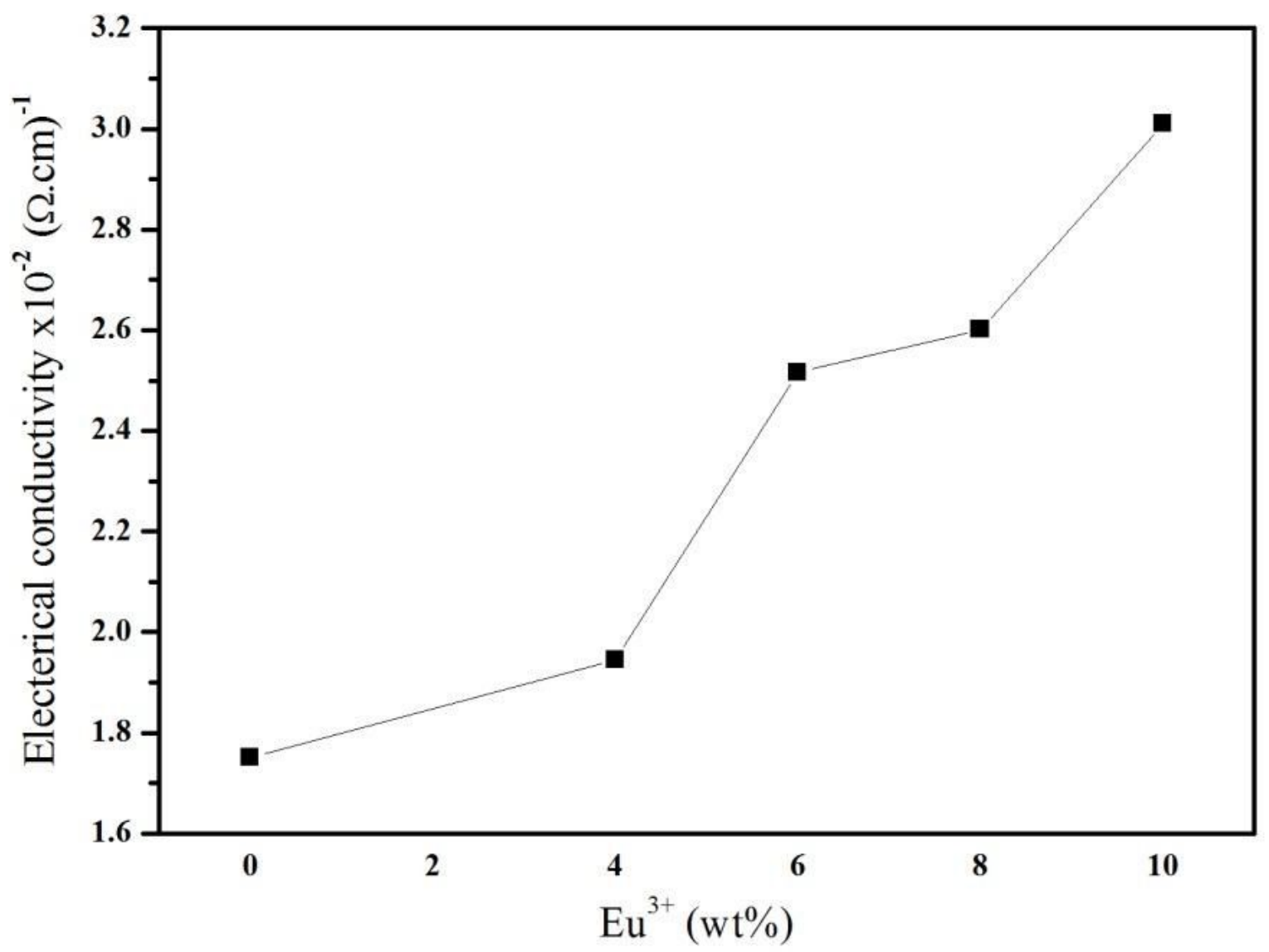

Figure 9

Effect of doping concentration on electrical conductivity of undoped and TiO2: Eu3+ thin films. 

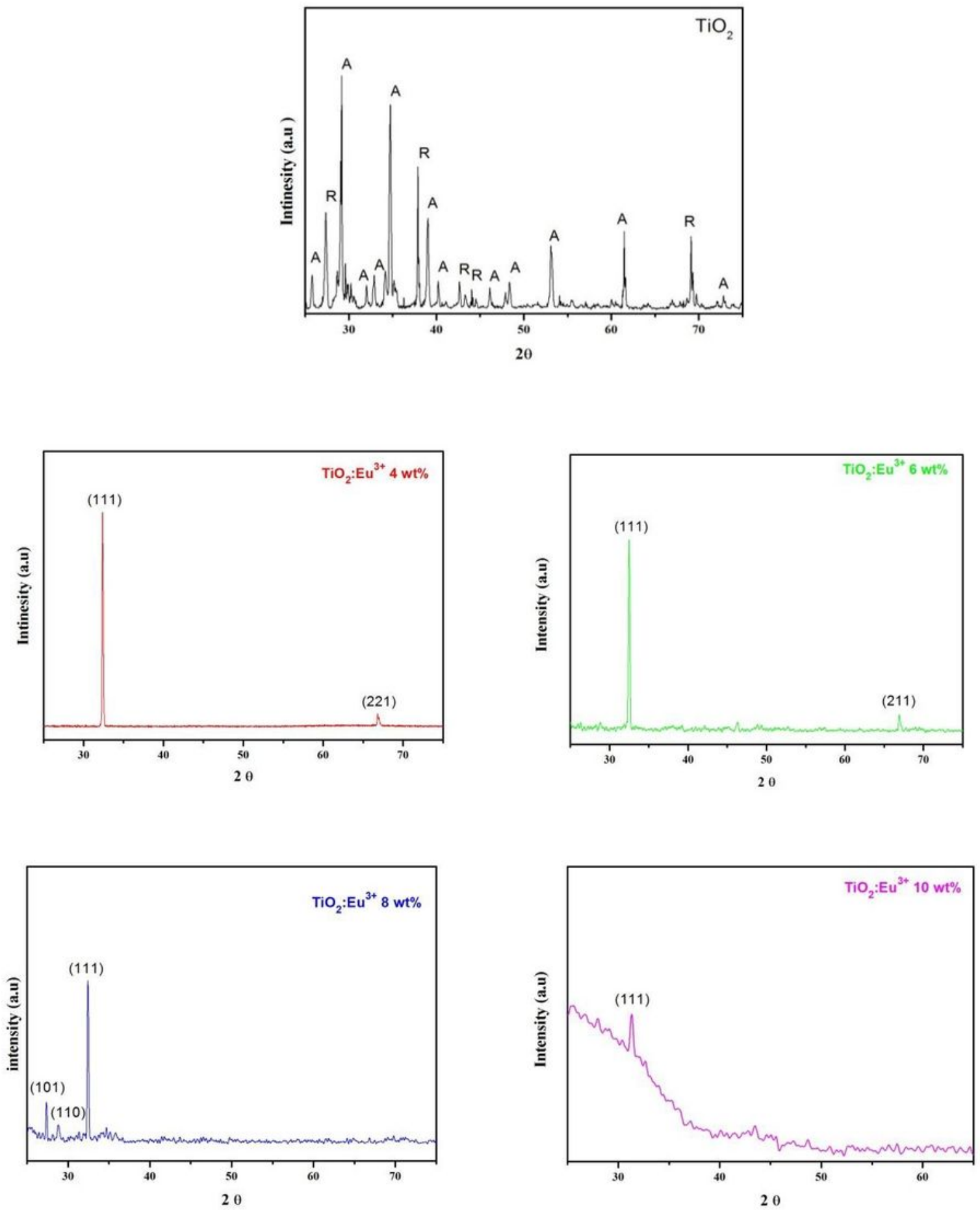

Figure 10

The XRD patterns of undoped and TiO2: Eu3+ thin films. 

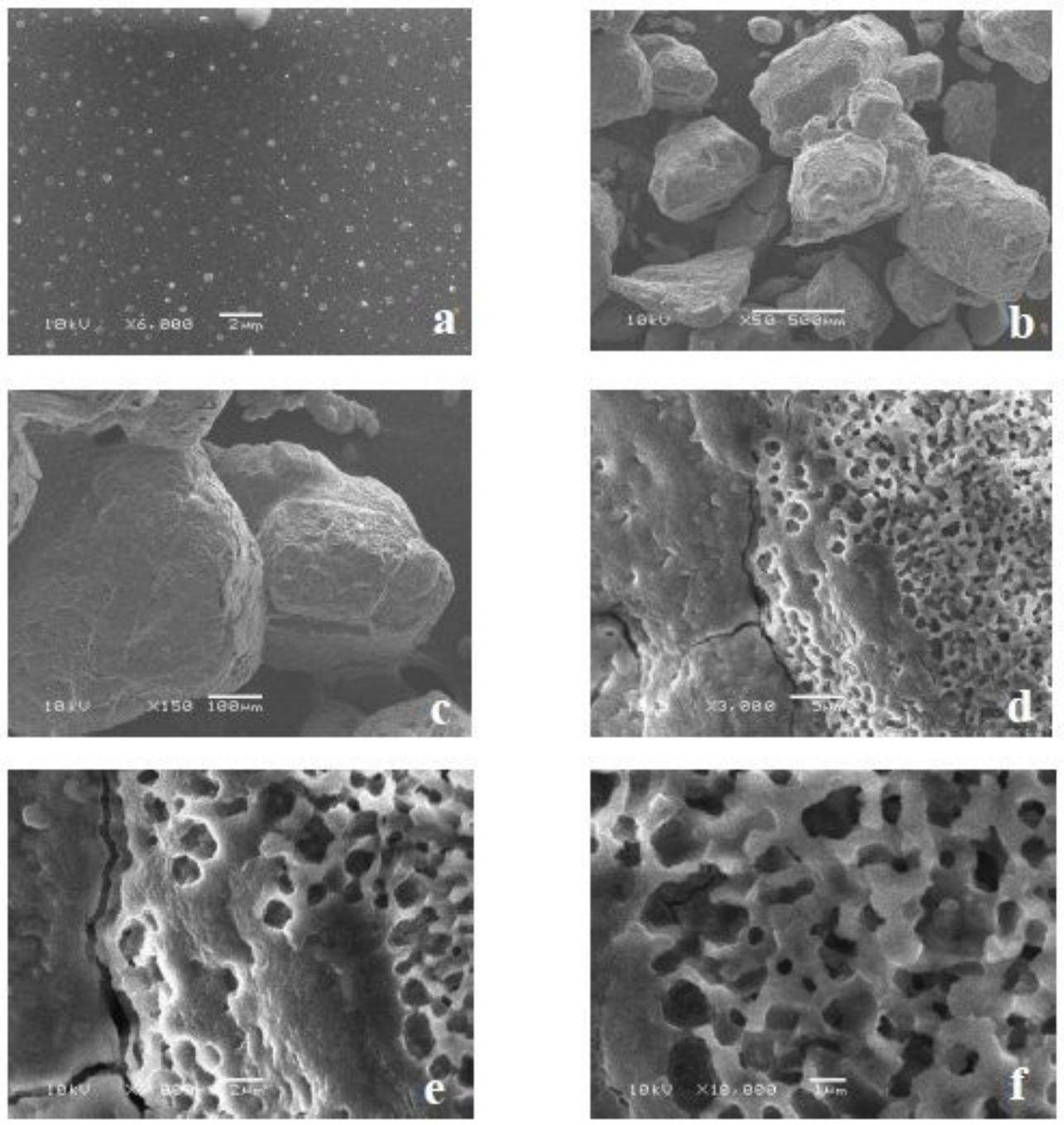

Figure 11

SEM images of ( a ) undoped and ( $b-f$ ) TiO2: Eu3+ thin films. 


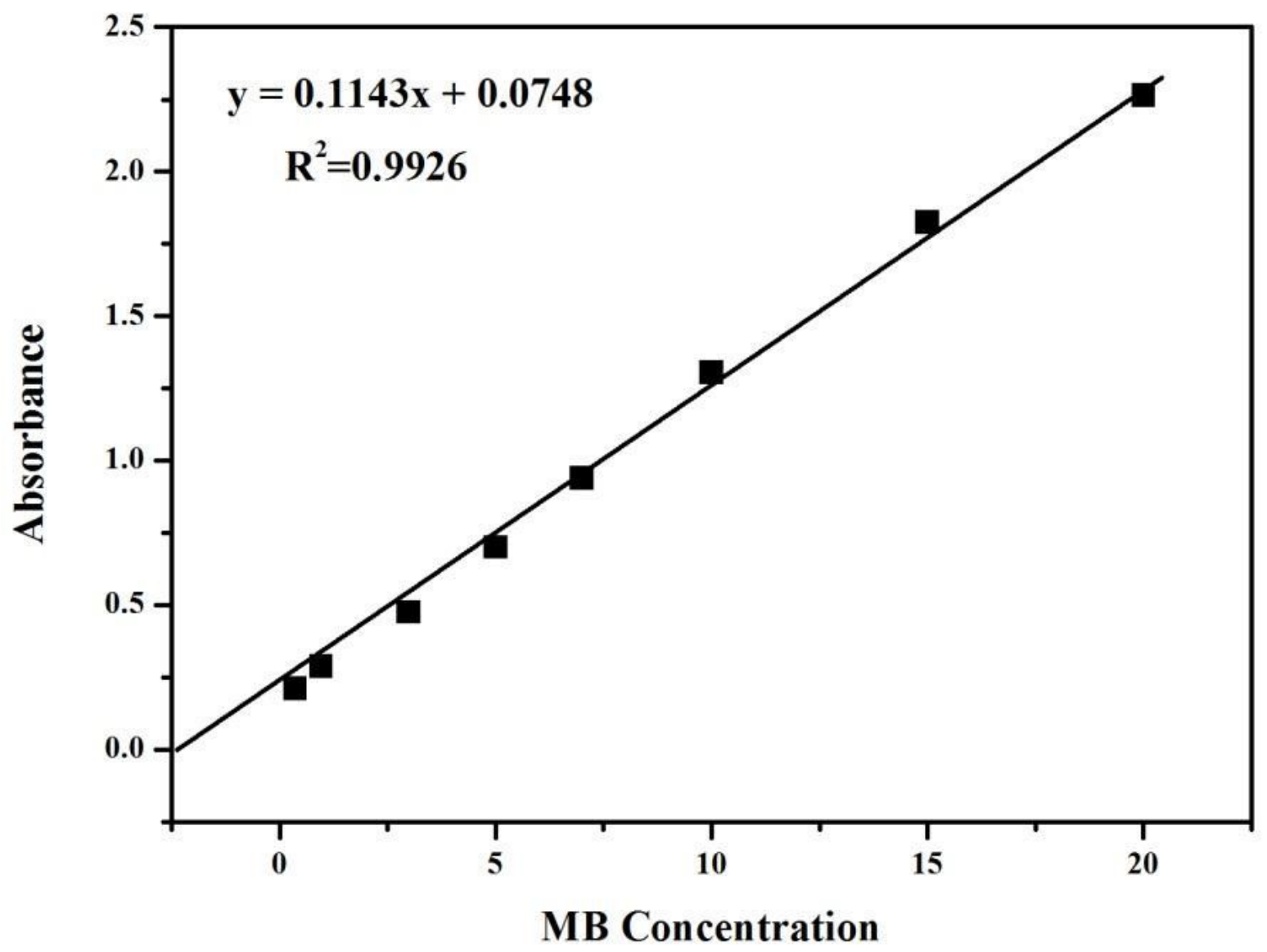

Figure 12

MB concentration curve with absorbance. 


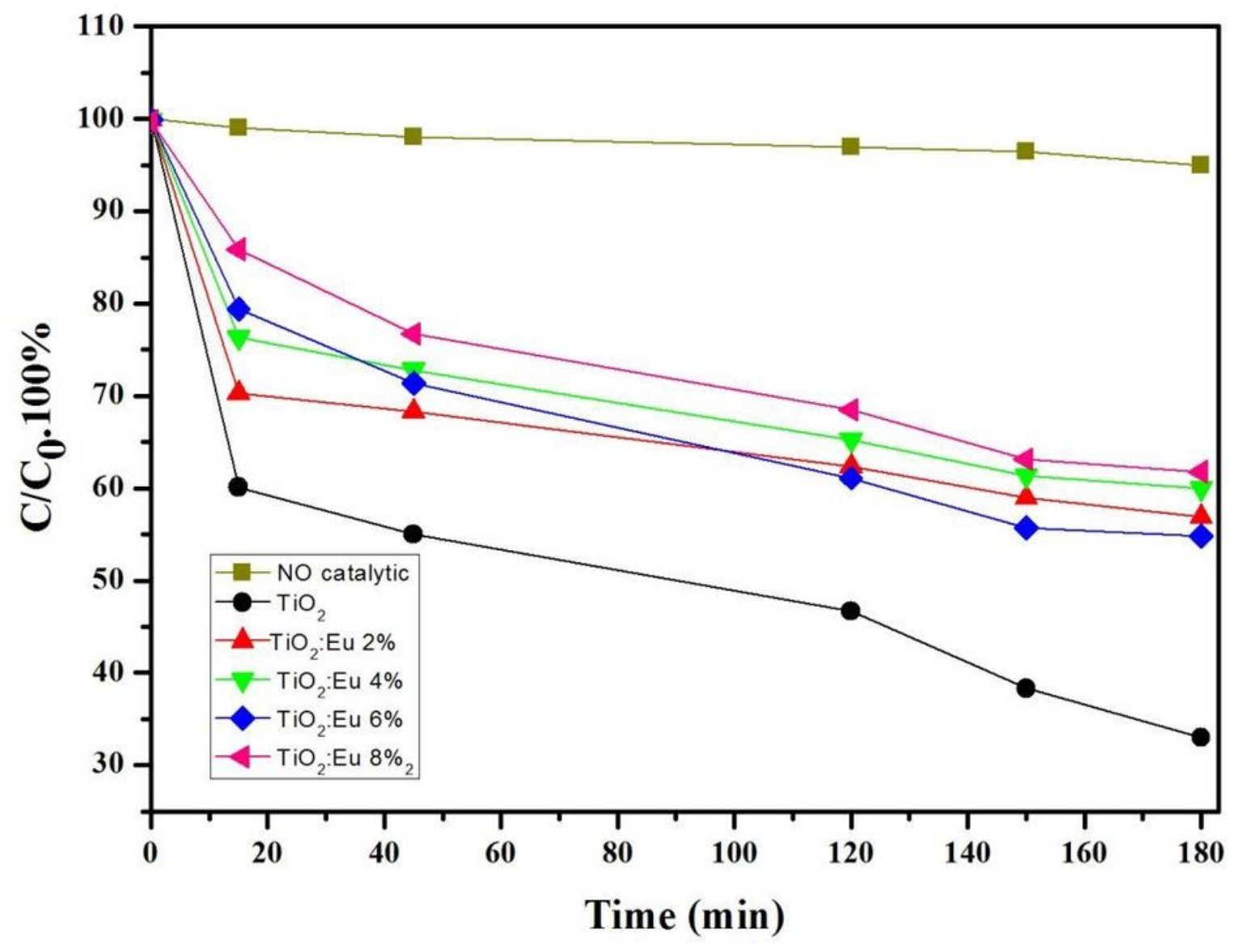

Figure 13

Degradation of MB using undoped and TiO2: Eu3+ thin films under UV light as a function of time. 


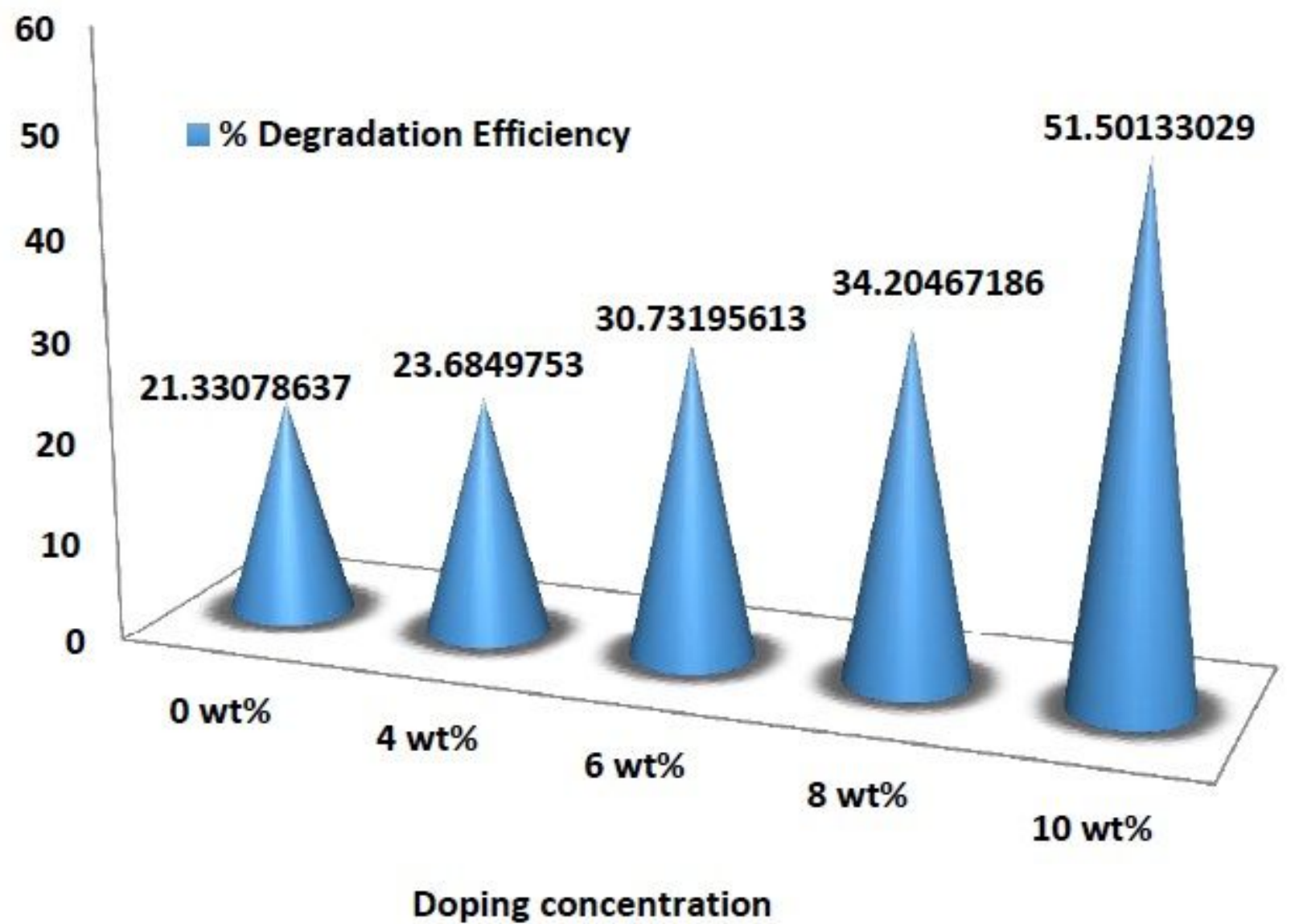

Figure 14

Degradation efficiency undoped and TiO2: Eu3+ thin films under UV light. 